\title{
O PILAR MANUTENÇÃO PLANEJADA DA MANUTENÇÃO PRODUTIVA TOTAL (TPM): APLICAÇÃ̃ DA MANUTENÇÃO CENTRADA EM CONFIABILIDADE (RCM)
}

\section{THE PILAR PLANNED MAINTENANCE OF THE TOTAL PRODUCTIVE MAINTENANCE (TPM): RELIABILITY CENTRED MAINTENANCE APPLICATION}

\author{
Giglliara Segantini de Menezes ${ }^{1}$; Maiquel Moreira Nunes Santos ${ }^{2}$; Gisele de Lorena Diniz Chaves ${ }^{3}$ \\ ${ }^{1}$ Universidade Federal do Espírito Santo (UFES) - São Mateus - ES - Brasil \\ giglliara@hotmail.com \\ ${ }^{2}$ Universidade Federal do Espírito Santo (UFES) - São Mateus - ES - Brasil \\ maisanto@gmail.com \\ ${ }^{3}$ Universidade Federal do Espírito Santo (UFES) - São Mateus - ES - Brasil \\ gisele.chaves@ufes.br
}

\begin{abstract}
Resumo
A confiabilidade de equipamentos ou de sistemas é uma das principais preocupações na gestão da manutenção. Ela proporciona maior disponibilidade e vida útil dos equipamentos, que se traduz em ganhos financeiros para a organização, principalmente quando o equipamento é considerado um gargalo ou um recurso com capacidade restrita (CCRs). Este trabalho trata da aplicação da Manutenção Centrada em Confiabilidade (RCM) como forma de encontrar a melhor estratégia de manutenção do pilar "manutenção planejada" da Manutenção Produtiva Total (TPM). O estudo de caso foi feito nas prensas de fardos de celulose das linhas de enfardamento da Suzano Papel e Celulose (SPC). Atualmente a prensa é um CCR, ou seja, tem capacidade superior à necessária, mas que em função das variabilidades que ocorrem nos sistemas produtivos, podem conjunturalmente apresentar restrições de capacidade. Devido aos elevados números de chamados de manutenção, que demandam grandes tempos de parada de linha, a empresa tem tido perdas de produção. Para encontrar a melhor estratégia de manutenção para as prensas, sua confiabilidade foi obtida com o auxílio do Software Reliasoft Weibull ++, identificando que as prensas se encontram no estágio de falhas aleatórias, da curva da banheira. Para os seus componentes críticos, que são as válvulas e bomba M3, levantou-se os tempos médio para falhas (MTBF) e seus tempos médio para reparo (MTTR), para então estabelecer orientações para elaboração do plano de manutenção da prensa tendo como base as atividades da gestão TPM.
\end{abstract}

Palavras-chave: gestão da manutenção; confiabilidade dos equipamentos; gestão TPM

\section{Introdução}

Alcançar níveis elevados de competitividade requer a busca pela excelência da manufatura que se fundamenta na redução de desperdício e no aprimoramento contínuo dos processos (BIASOTTO, 2006; CHIAVENATO, 1999). Para alcançar o aumento da produtividade dos 
sistemas produtivos, as empresas passam a adotar a manutenção industrial como uma das atividades de apoio à produção para melhoramento dos níveis de competitividade (LUCATELLI, 2002; LAFRAIA 2008).

Tais mudanças nos negócios e na estratégia de manufatura não se atentam somente a manter as condições originais dos equipamentos, visam também proporcionar aumento da produtividade por meio da redução de custos, aumento de confiabilidade e disponibilidade dos equipamentos considerados críticos para o processo produtivo (MÁRQUEZ et al., 2009; XENOS, 2004).

A abordagem estratégica da manutenção vem sendo difundida por meio de conjuntos de várias técnicas e políticas que estabelecem formas de atingir o funcionamento da produção em sistemas cada vez mais complexos (SILVA, 2010). Estão neste conjunto a abordagem da Manutenção Produtiva Total - TPM (Total Productive Maintenance), e a Manutenção Centrada na Confiabilidade - MCC ou RCM (Reability Centred Maintenance) (KELLY, 2002; FOGLIATTO; RIBEIRO, 2011).

A RCM e a TPM são metodologias complementares: os fundamentos da RCM têm a função de agregar valor às implantações da TPM num modo bastante específico. Assim, a RCM possui a função de determinar o que deve ser feito e porque deve ser feito, enquanto a TPM tem características de logística, pois determina como deve ser feito. Essas metodologias da manutenção demonstram que as organizações estão preocupadas com os ativos físicos tanto no campo da investigação por profissionais quanto no desenvolvimento por parte de estudiosos (GERAGHETY, 1996).

Neste sentido, este trabalho tem como objetivo principal avaliar e propor melhorias à gestão da manutenção, da empresa estudada, utilizando a RCM (Reliability Centred Maintenance ou Manutenção Centrada em Confiabilidade) para encontrar melhores estratégias de manutenção planejada, de acordo com a filosofia TPM, Espera-se propor modificações nos planos de manutenção que minimizem os impactos das falhas no equipamento analisado, com consequente melhoria do tempo médio de reparo (MTTR).

\section{Referencial bibliográfico}

\subsection{Manutenção}

Com o grande aumento no número e variedade de itens físicos, como instalações, equipamentos e ferramentas, a manutenção teve que evoluir para garantir o funcionamento de projetos de equipamentos e sistemas produtivos cada vez mais complexos (MOUBRAY, 2000). Porém a essência do conceito de manutenção permanece com a mesma aplicabilidade. Para Gits (1992), no sistema de produção existe a entrada primária (inputs) que é processada e transformada 
em saídas (outputs). Essa etapa de agregação de valor é feita por meio de sistemas técnicos. Esses por sua vez, são definidos como sendo os elementos físicos fundamentação para que ocorra o preenchimento da função. Porém o sistema técnico está sujeito a variáveis aleatórias, externas e intrínsecas ao seu ambiente, que conduzem consequentemente a uma saída secundária, a demanda por manutenção. Portanto, manutenção é o total de atividades requeridas para manter os sistemas, ou restaurá-los ao estado necessário para executar a função de produção (FOGLIATTO; RIBEIRO, 2011).

Um sistema reparável é aquele que, após falha, pode ser retornado à condição de operação por meio de um reparo. Os reparos não precisam, necessariamente, envolver a substituição das partes do sistema. Já nos sistemas não reparáveis essas partes são descartadas após a primeira e única falha. Um ponto importante é a viabilidade de trabalhar com reparos, pois existem sistemas que ao apresentarem uma falha poderiam ser reparados, mas o custo do reparo é maior que o da substituição de alguma peça ou o conserto de alguma máquina. Assim o sistema acaba sendo considerado como não reparável na prática (RIGDON; BASU, 2000).

Modelos de melhoramento da produção buscam formas de prevenção para que as falhas não ocorram, buscando combater as causas de perdas e falhas no processo produtivo (SLACK; CHAMBERS; JOHNSTON, 2008). A análise do comportamento da taxa de falha de um equipamento ao longo do tempo pode ser representada por uma curva denominada como curva da banheira, como na Figura 1. A curva representa as diferentes etapas da vida de um equipamento que envolvem a probabilidade dele falhar. As fases da vida características de um sistema são a mortalidade infantil, a maturidade e a mortalidade (SELLITTO, 2005).

A mortalidade infantil ou etapa de vida inicial é caracterizada por falhas iniciais que ocorrem por causa de peças defeituosas ou uso inadequado. Neste período, a melhor estratégia de manutenção é a corretiva, ou seja, cabe à manutenção não apenas reparar o equipamento, mas corrigi-lo, para que a falha não se repita. A maturidade ou vida normal é caracterizada por taxas de falhas normalmente baixas e constantes, sendo causadas por fatores aleatórios normais. Neste período, a melhor estratégia de manutenção é a preditiva, ou seja, monitoramento para detectar o início da fase de desgaste. A etapa de mortalidade senil ou desgaste é caracterizado por um aumento na taxa de falhas à medida que a peça ou equipamento se aproxima do fim da sua vida útil, sendo as falhas causadas geralmente por desgastes e deterioração. Neste período, a melhor estratégia de manutenção é a preventiva, ou seja, já que o equipamento irá falhar, cabe à manutenção achar o melhor tempo para substituir ou reformar o item. (SELLITTO, 2005; SLACK; CHAMBERS; JOHNSTON, 2008). 
Figura 1 - Curva da Banheira e ciclo de vida de equipamentos

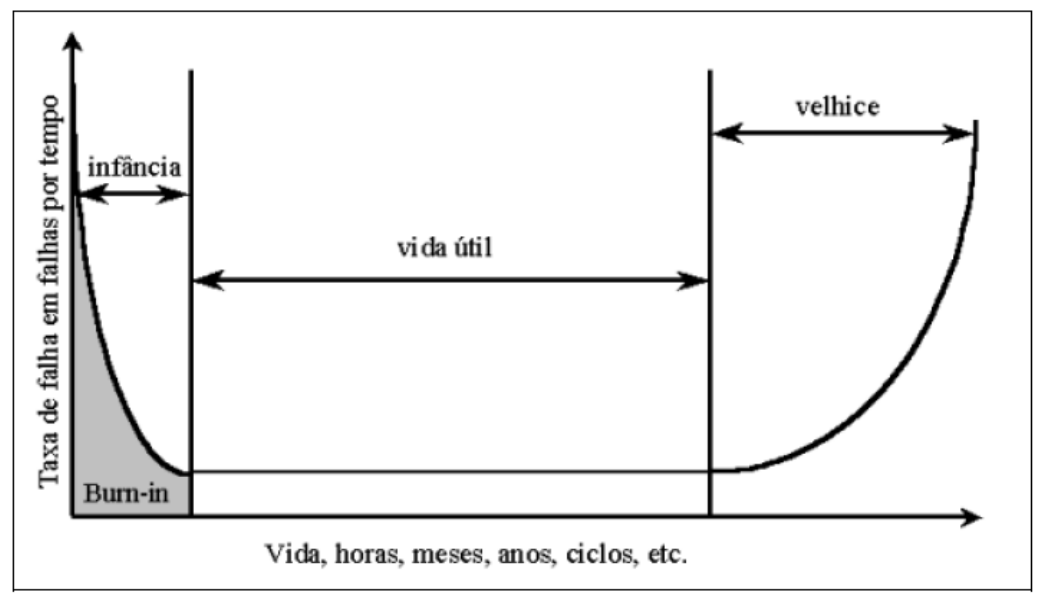

Fonte: Silva (2012)

Tendo em vista a importância de se avaliar as falhas para a proposição da manutenção dos equipamentos, Slack, Chambres, Johnston (2008) e Hansen (2006) propuseram várias formas de medir falhas. São elas:

a) Taxa de falhas: avalia a frequência da ocorrência de uma falha. Seu cálculo é expresso pela Equação 1;

$$
T F=\frac{\text { Número de Falhas }}{\text { Tempo de Operação }}
$$

b) Confiabilidade: avalia a probabilidade de uma falha ocorrer. Uma das técnicas mais usadas para aumentar a confiabilidade é o uso de redundância. Introduzir redundância em uma produção significa ter sistemas ou equipamentos de reserva para quando ocorrerem as falhas. Sua expressão é vista na Equação 2, sendo que $R_{a+b}$ representa a confiabilidade do componente a com seu componente $\mathrm{b}, R_{a}$ é a confiabilidade de $a, R_{b}$ é a confiabilidade do componente reserva $b$ e $P($ falha $)$ é a probabilidade de que o componente $a$ falhe e, portanto, o componente $b$ seja necessário;

$$
R_{a+b}=R_{a}+\left(R_{b} x P(\text { falha })\right)
$$

c) Tempo médio entre falhas (TMEF): avalia o tempo em que não ocorreram falhas e sua expressão é o inverso da taxa de falhas, conforme Equação 3;

$$
T M E F=\frac{\text { Tempo de Operação }}{\text { Número de Falhas }}
$$

d) Disponibilidade (D): avalia o nível em que a operação está efetivamente disponível para funcionamento. Seu cálculo é descrito na Equação 4 e envolve os tempos médios até falhas (MTBF) e o tempo médio de reparo (MTTR); 


$$
(D)=\frac{M T B F}{M T B F+M T T R}
$$

\subsection{Tipos de manutenção}

Moubray (1997) define como políticas de manutenção tradicionais a manutenção corretiva (MC), a manutenção preventiva (MP) e a manutenção preditiva (MPd), acrescentando a manutenção detectiva (MD). Para Vizzoni (1998) e Smith (1993) a manutenção é dividida em duas grandes categorias, a manutenção corretiva e a preventiva. Dentro da MP estão as técnicas de MPd e a MD. Corroborando desta definição, Carpio et al. (1999) subdividem a MP em duas subcategorias de manutenção: manutenção preventiva sistemática, considerada a tradicional, e manutenção preventiva condicional que é a MPd.

Para Kardec e Nascif (1999) o mais adequado é dividir a manutenção em seis diferentes tipos, sendo eles: MC não planejada, MC planejada, MP, MPd, MD e engenharia de manutenção. Os autores ressaltam ainda que a aplicação gera como resultado uma definição gerencial, caraterística esta que torna os tipos de manutenção como uma política. Sob o ponto de vista da Manutenção Centrada na confiabilidade a classificação mais pertinente é a adotada por Patton (1995), uma vez que há a estratificação da manutenção em não planejada e a planejada (ZAIONS, 2003).

A manutenção não planejada é estritamente corretiva, ou seja, consiste na correção da falha após a sua ocorrência aleatoriamente. Esse tipo de ocorrência gera perdas de produção, perdas de qualidade do produto e elevados custos (LUCATELLI, 2002). O conjunto de ações adotadas para a diminuição ou eliminação das perdas de produção buscadas pela manutenção planejada, que envolvem um acompanhamento preditivo e detectivo, encontram-se na Figura 2.

Figura 2 - Métodos de manutenção planejada

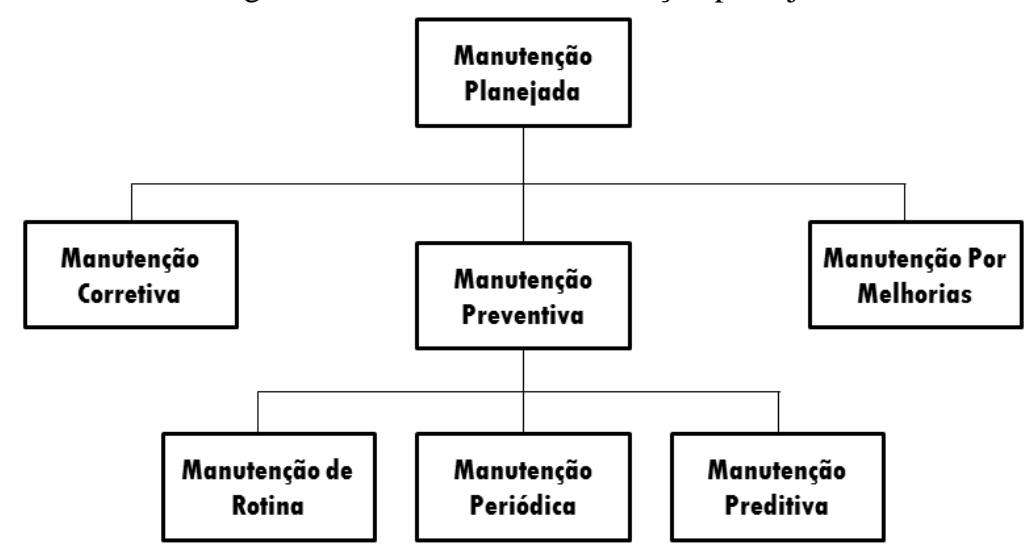

Fonte: Zaions (2003)

A MC é a atividade de manutenção que exige a correção de uma falha ocorrida ou que esteja no momento da ocorrência. Esta atividade pode consistir em reparo, restauração ou substituição de 
componentes (MOUBRAY, 1997). A MC, por ser mais antiga nos sistemas de produção de qualquer setor, possui políticas amplamente difundidas, além de existirem diversos autores na literatura que abordam seus conceitos e métodos tais como Branco Filho (2000); Kardec e Nascif (1999); e Mirshawa e Olmedo (1993).

Uma das principais vantagens da MC é a não exigência de planejamento, enquanto estratégia. De certa forma, existe um nível necessário de planejamento quanto a ferramental, manuais, peças de reposição e funcionários treinados para a execução das tarefas. Como desvantagens, a MC necessita de um grande estoque de peças sobressalentes, suas paradas são caras, inconvenientes e demoradas, além do desconhecimento do estado técnico do sistema (KARDEC e NASCIF, 1999).

Já a MP consiste na intervenção de manutenção prevista, preparada e programada antes da data provável do aparecimento de uma falha, ou seja, a ação tomada para manter um item físico em condições operantes por meios de inspeções, detecção, prevenção de falhas, reformas e troca de peças (WIREMAN, 1998; XENOS, 2004). Essas atividades são realizadas num certo intervalo, sendo estes definidos com base no tempo de calendário, número de horas trabalhadas e número de partidas de um sistema qualquer (HANSEN, 2006; PALMER, 2000; PALARCHIO, 2002; KARDEC; NASCIF, 1999).

Para Pinto e Xavier (2005), a MP apresenta como vantagens: a continuidade do funcionamento das máquinas, só parando para consertos em horas programadas; maior facilidade para cumprir seus programas de produção; e a previsibilidade de consumo de materiais e sobressalentes. O consumo de materiais como peças e componentes dos equipamentos, que são trocados ou reformados antes de atingirem seus limites de vida, tornam a MP uma modalidade de manutenção custosa. Portanto, suas principais desvantagens são: requerer um programa bemestruturado; necessitar de uma equipe de mecânicos eficazes e treinados; requerer um plano de manutenção; e a necessidade de trocar peças antes que seus limites de vida útil sejam alcançados (WYREBSKI, 1997).

A MP se divide em manutenção de rotina, manutenção periódica e manutenção preditiva. A manutenção de rotina é definida como intervenções leves, efetuadas em intervalos de tempos predeterminados. As tarefas desse tipo de manutenção normalmente são executadas durante os dias de operação, sendo responsabilidade tanto da manutenção como também de todos os operadores dos itens físicos (BRANCO FILHO, 2000; XENOS 2004).

A manutenção periódica é também chamada de sistemática ou programada, e é considerada em uma evolução natural da manutenção preventiva. Sua atuação implica no acompanhamento dos históricos dos registros, que permiti a elaboração de gráficos de controle estatístico das máquinas. Sua utilização permite ampliar os conhecimentos sobre as falhas nos equipamentos. No entanto, 
geram-se custos adicionais para a execução da tomada de dados utilizados para elaborar a manutenção periódica (BRANCO FILHO, 2000).

O controle preditivo de manutenção determina o ponto ótimo para executar a manutenção preventiva no equipamento, ou seja, o ponto a partir do qual a probabilidade de o equipamento falhar assume valores indesejáveis (TAVARES, 1999). Seu enfoque acompanha o comportamento de determinadas variáveis do equipamento ou identifica um componente com desempenho diferente do esperado. Constatada a anomalia, realiza-se a manutenção (WIREMAN, 1998; MIRSHAWKA; OLMEDO 1993).

Por sua vez, a manutenção por melhorias vai além do conserto das falhas, ela busca alterar as especificações originais do equipamento para garantir o melhoramento gradativo e contínuo. Conforme necessário, a alteração do projeto, seus padrões de operação e manutenção, podem ocorrer. Este tipo de manutenção busca eliminar um dos pontos fracos da manutenção nas empresas brasileiras, em que a manutenção é considerada completa ao se consertar o defeito e restituir o item à sua condição operacional (PALMER, 2000). Segundo Zaions (2003), a maioria das melhorias adotadas em equipamentos para resolução de falhas é pequena e de baixo custo. Em compensação, existem também melhorias que necessitam de significativas mudanças no equipamento ou até mesmo no processo de produção que, apesar de menos frequentes, impactam em maiores mudanças e custos.

As vantagens e desvantagens dos tipos de manutenção são sintetizadas no Quadro 1.

\begin{tabular}{|c|c|c|}
\hline TIPO & VANTAGENS & DESVANTAGENS \\
\hline \multirow{3}{*}{$\begin{array}{l}\text { MANUTENÇÃO } \\
\text { CORRETIVA }\end{array}$} & \multirow{3}{*}{$\begin{array}{l}\text { Os custos envolvidos em um eventual } \\
\text { reparo são inferiores aos custos de } \\
\text { manutenção preventiva. }\end{array}$} & Altos custos de mão-de-obra, peças e serviços. \\
\hline & & Tempo de máquina e instalações inoperantes. \\
\hline & & Causar perda de produção. \\
\hline \multirow{4}{*}{$\begin{array}{l}\text { MANUTENÇÃO } \\
\text { PREVENTIVA }\end{array}$} & $\begin{array}{l}\text { A continuidade do funcionamento das } \\
\text { máquinas, só parando para consertos } \\
\text { em horas programadas. }\end{array}$ & Requer um programa bem-estruturado. \\
\hline & \multirow{2}{*}{$\begin{array}{l}\text { Maior facilidade para cumprir seus } \\
\text { programas de produção. }\end{array}$} & $\begin{array}{l}\text { Necessita de uma equipe de mecânicos eficazes e } \\
\text { treinados. }\end{array}$ \\
\hline & & $\begin{array}{l}\text { As peças são trocadas antes de atingirem seus limites } \\
\text { de vida. }\end{array}$ \\
\hline & $\begin{array}{l}\text { Previsibilidade de consumo de } \\
\text { materiais e sobressalentes. }\end{array}$ & $\begin{array}{l}\text { Requer um plano detalhado estrategicamente de } \\
\text { manutenção. }\end{array}$ \\
\hline \multirow{3}{*}{$\begin{array}{l}\text { MANUTENÇÃO } \\
\text { POR } \\
\text { MELHORIAS }\end{array}$} & $\begin{array}{l}\text { Resolução de falhas pequenas e de } \\
\text { baixo custo. }\end{array}$ & \multirow{3}{*}{$\begin{array}{l}\text { Resolução de falhas com melhorias que necessitam } \\
\text { significativas mudanças no equipamento ou até mesmo } \\
\text { no processo de produção. }\end{array}$} \\
\hline & $\begin{array}{l}\text { Quando o tempo de reparo é elevado e } \\
\text { há possibilidade de propagação da } \\
\text { falha. }\end{array}$ & \\
\hline & $\begin{array}{l}\text { Quando o tempo médio entre falhas é } \\
\text { grande, proporcionando dificuldades de } \\
\text { avaliação e inspeção. }\end{array}$ & \\
\hline
\end{tabular}

Fonte: Dados da Pesquisa 


\subsection{Gerenciamento da manutenção}

\subsubsection{Manutenção produtiva total}

Dentro do campo do gerenciamento da manutenção existe a Manutenção Produtiva Total (TPM). Essa por sua vez abrange o conceito de forma mais ampla da manutenção preventiva, baseada na viabilidade econômica de reparos ou aquisições de equipamentos que desempenham os papéis mais importantes na produção. A TPM cria um autogerenciamento no local de trabalho, ou seja, a manutenção passa a ser realizada pelo operador do equipamento ou máquina, uma vez que os operadores assumem a propriedade de seu equipamento e passam a mantê-los. Seu elo entre a execução tem por fundamentos a relação potencial de conhecimento do operador adquirido ao longo dos anos na empresa (TAKAHASHI; OSADA, 1993).

Segundo Nakajima (1989), os principais objetivos da TPM são: o aumento da confiabilidade dos equipamentos, a eliminação das quebras e melhorias do índice de disponibilidade das máquinas. Por meio do gerenciamento homem e máquina para a melhoria estrutural da empresa, os funcionários são capacitados tecnicamente e conscientizados sobre a importância do desempenho do equipamento. Porém, os treinamentos são investimentos de longo prazo que geram como benefícios a multifuncionalidade dos operadores, senso de responsabilidade, redução no tempo de reparo e integração entre operadores e mecânicos.

A implantação TPM é consolidada em oito pilares básicos, sendo que eles variam conforme a estrutura e filosofia que cada escritor usa. Os 8 pilares do TPM. Na base do TPM encontram-se as pessoas, desde operadores até a mais alta presidência, pois o sucesso do programa depende da participação e conscientização de todos, bem como de treinamento e educação dessas pessoas. Em seguida temos a filosofia 5S, que apesar melhoria de estar incluso na descrição do primeiro pilar, é fundamental para qualquer iniciativa que envolve a contínua (NAKAJIMA 1989).

a) Manutenção Autônoma: É a manutenção dos equipamentos feita pelos operadores, para garantir alto nível de produtividade. As atividades de Manutenção Autônoma começam nos equipamentos e se estendem a toda produção. O objetivo deste pilar é conscientizar o operador de sua responsabilidade com seu equipamento de trabalho através das atividades da manutenção autônoma;

b) Manutenção Planejada: É o pilar responsável por todo o planejamento da manutenção em seu nível macro. A responsabilidade pela gestão desse pilar é do setor de manutenção da empresa e seus executores são os mantenedores, os quais têm formação técnica que permite maior conhecimento dos equipamentos. O objetivo é aumentar a eficiência global dos equipamentos (IROG), com aumento da disponibilidade operacional; 
c) Melhoria Específica: Responsável pelo gerenciamento das informações de funcionamento dos equipamentos. O objetivo é desenvolver melhoria contínua ao processo de manutenção de equipamentos;

d) Educação e Treinamento: Gestão responsável pelo controle do conhecimento dos operadores, mantenedores e lideranças inseridas na Manutenção;

e) Controle Inicial: A execução de manutenção de equipamentos pode ter deficiência por falta de informações referentes ao histórico de funcionamento. É imprescindível, assim, uma gestão unificada de manutenção de novos equipamentos;

f) Manutenção da Qualidade: Através do eficiente reparo das máquinas de produção a TPM tem como meta "zero defeito" de produtos. O setor responsável por controle de qualidade e gerenciamento do sistema de gestão de qualidade deve atuar em conjunto com a gestão da manutenção, para atingir os objetos comuns;

g) Administração: É o uso da metodologia da Manutenção Produtiva Total, em todos os setores de uma empresa. O objetivo é reduzir perdas administrativas;

h) Segurança, Saúde e Meio Ambiente: Frente de gestão que objetiva o nível zero de acidentes ambientais e do trabalho. Desta forma, o pressuposto para boa gestão dessa frente é manter o ambiente de trabalho em boas condições, limpo e seguro.

O Sistema Toyota de Produção entende a TPM como ciclos gerenciais de rotina, melhorias e desenvolvimento de produtos e processos da Gestão de Qualidade Total. A TPM é uma importante ferramenta para a sincronização da produção (ANTUNES et al., 2008). Nas empresas, a cultura já existente e a nova cultura a ser implantada para viabilizar a TPM são fatores que influenciam na adequação desses pilares visando à minimização das perdas de produção (NAKAJIMA, 1989).

\subsubsection{Manutenção Centrada na Confiabilidade (RCM)}

A RCM é uma forma lógica de levantar quais equipamentos da empresa devem trabalhar com a manutenção preventiva e quais equipamentos devem ser selecionados para rodar até falhar (BLOOM, 2006; FOGLIATTO; RIBEIRO, 2011). A definição da RCM, segundo Fogliatto e Ribeiro (2011), é bastante abrangente no sentido de reunir várias técnicas de engenharia para assegurar que o equipamento realizará suas funções planejadas e esperadas com o custo reduzido. Portanto, pode-se dizer que o conceito de RCM é encontrar a probabilidade de um equipamento ou componente cumprir sua função com sucesso, por meio do tempo previsto e por condições de trabalho específicas. O principal objetivo deste tipo de gerenciamento de manutenção é a criação de rotina que preserve funções de sistemas e equipamentos (LAFRAIA, 2008).

Os benefícios com a aplicação da RCM para a participação no aumento dos lucros por meio de: menos paradas não programadas, menos custo de manutenção/operação/apoio e menor 
possibilidade de acidentes. Para isso, trabalha com a eliminação das causas básicas de paradas não programadas, de forma a atuar com histórico de falhas dos equipamentos, determinação das causas básicas das falhas, prevenção de falhas em equipamentos similares e determinação de fatores críticos para a manutenabilidades ${ }^{1}$ de equipamentos (LAFRAIA, 2008).

Os principais aspectos da RCM referem-se ao reconhecimento de falhas que podem acarretar custos de uma manutenção preventiva maiores que o custo associado às perdas operacionais e ao reparo do equipamento. Isso é um fator que cria desvantagens para manutenção a menos que envolva requisito normativo ou relacionado à segurança ou meio ambiente (BLOOM, 2006).

Para Deshpande e Modak (2002), devem-se equilibrar os tipos de manutenção para se alcançar a otimização necessária para a empresa. Para isso, existem métodos qualitativos para a definição do tipo de manutenção e do intervalo entre manutenções a ser adotado. Estes métodos utilizam da experiência da equipe de manutenção para estabelecer o intervalo entre manutenções, além de disso, trabalham-se com os históricos de informações referentes à evidência da falha, suas consequências e aplicabilidade das atividades de manutenção (RAUSAND, 1998; BLOOM, 2006; FOGLIATTO; RIBEIRO, 2011).

Visando uma abordagem quantitativa, cada tipo de equipamento apresenta uma densidade de probabilidade que identifica suas falhas ao longo da vida útil, por isso através da análise desses dados é possível definir o tipo de manutenção que seja mais adequada para cada equipamento (LAFRAIA, 2008; SELLITTO, 2005).

Para Lafraia (2008), o que define a escolha do tipo de manutenção é a distribuição dos tempos de falha dos equipamentos. Como cada equipamento se comporta de forma diferente, seria ineficaz apenas uma análise qualitativa das informações. Assim, a definição do tempo entre as manutenções depende de uma descrição matemática do processo de falha do equipamento (RAUSAND, 1998).

A função densidade de falhas representa a variação da probabilidade de falhas por unidade de tempo. É representada graficamente por uma função, distribuição de probabilidade e é expressa pela Equação 5 (LAFRAIA,2008).

$$
f(t)=\frac{d F(t)}{d t}
$$

A expressão matematica da $F(t)$, que representa a função acumulada de falhas, ou seja, mostra a probabilidade de falhas entre os períodos determinados $\left(t_{1} e t_{2}\right)$ é vista pela Equação 6 (LAFRAIA, 2008).

\footnotetext{
${ }^{1}$ Manutenabilidade (ou mantenabilidade), segundo a Norma Brasileira Registrada NBR 5462 (1994), é a facilidade de um item em ser mantido ou recolocado no estado no qual pode executar suas funções requeridas, sob condições de uso especificadas, quando a manutenção é executada sob condições determinadas e mediante procedimentos e meios descritos.
} 


$$
F\left(t_{2)}-F\left(t_{1}\right)=\int_{t_{1}}^{t_{2}} f(t) d t\right.
$$

Para encontrar a probabilidade de um equipamento manter suas funções em um dado intervalo de tempo de 0 a $\infty$ é estabelecido a seguinte Equação, 7, de confiabilidade $C(t)$ (LAFRAIA, 2008).

$$
C(t)=\int_{t}^{\infty} f(t) d t=1-\int_{-\infty}^{t} f(t) d t=1-F(t)
$$

Logo, $F(t)$ é a probabilidade de falha no sistema. A Equação 11 descreve a proporção das falhas que ocorrem ao longo do tempo, mas essa proporção é tomada em relação ao tamanho da população no tempo $t=0$, mas o que se torna relevante é uma função que informe a proporção da população sobrevivente que deve falhar no próximo intervalo de tempo. Para isso, os cálculos para encontrar a confiabilidade de um equipamento necessitam de somente dois tipos de informações: o número total de falhas em um período de interesse e o tempo total acumulado de operação para o período de interesse (BERGAMO, 1997).

Uma forma de quantificar a confiabilidade de um sistema é através do Tempo Médio até a Falha (MTBF) para sistemas não reparáveis. Enquanto a confiabilidade tenta reduzir a frequência de falhas em sistemas, a manutenabilidade concentra-se em diminuir o tempo da duração de falhas em um sistema e reestabelecer o funcionamento no menor tempo possível. De forma simplificada, a Equação pode ser estimada conforme descrito por Elsayed (1996) na Equação 8.

$$
M T B F=\frac{1}{n} \sum_{i=1}^{n} t_{i}
$$

\subsubsection{Distribuições estatísticas aplicadas à confiabilidade}

A escolha do modelo matemático estatístico a ser utilizado está diretamente relacionada aos tipos de testes de falhas realizados, bem como ao tamanho e tipo de amostragem analisada. As principais funções utilizadas são: Exponencial, Normal, Gama, Log-normal, Weibull (BERGAMO, 1997). Este trabalho abordará a distribuição de Weibull para representar o comportamento das falhas das prensas. Essa distribuição explica o comportamento de sistemas quando: as falhas são oriundas da competição entre diversos modos de falha, exemplos são os equipamentos industriais; como também descreve os casos em que a taxa de falha é crescente, decrescente ou constante (SELLITTO, 2005).

A função distribuição de Weibull possui três parâmetros para determinar a probabilidade de falha, confiabilidade e taxa instantânea. O Quadro 2 detalha essas expressões. 
Quadro 2 - Expressões e parâmetros da função weibull

\begin{tabular}{|c|c|c|}
\hline SIGNIFICADO & PARÂMETRO & EXPRESSÃO \\
\hline Distribuição de falhas & $f(t)$ & $\begin{array}{c}\frac{\beta}{\eta^{\beta}}\left(t-t_{0}\right)^{\beta-1} \exp \left[-\left(\frac{t-t_{0}}{\eta}\right)^{\beta}\right] \text { para } \frac{p}{t} \geq 0 \\
0 \text { para } \frac{p}{t}<0\end{array}$ \\
\hline $\begin{array}{l}\text { Probabilidade } \\
\text { Acumulada de Falhas }\end{array}$ & $\mathrm{F}(\mathrm{t})$ & $1-\exp \left[-\left(\frac{t-t_{0}}{\eta}\right)^{\beta}\right]$ \\
\hline Confiabilidade & $C(t)$ & $\exp \left[-\left(\frac{t-t_{0}}{\eta}\right)^{\beta}\right]$ \\
\hline $\begin{array}{l}\text { Taxa de falhas } \\
\text { instantâneas }\end{array}$ & $\lambda(\mathrm{t})$ & $\frac{\beta}{\eta}\left[-\left(\frac{t-t_{0}}{\eta}\right)^{\beta}\right]$ \\
\hline Parâmetro de forma & $\eta$ & \\
\hline Vida inicial & $t_{0}$ ou $\gamma$ & \\
\hline Tempo para a falha & $\mathrm{t}$ & \\
\hline
\end{tabular}

Fonte: LAFRAIA (2008)

A distribuição de probabilidade no modelo de Weibull possui parâmetros que devem ser estimados. São eles: $\eta$ e $\beta$, alguns autores utilizam $\gamma e \theta$. Estes parâmetros são definidos partir dos dados amostrais (FALCETTA, 2000). Um método bastante utilizado para determinação, ou seja, estimação de parâmetros Weibull é por mínimos quadrados. Uma vez que a linha foi desenhada, o declive da linha é o parâmetro $\beta$. Para determinar o parâmetro de escala, $\eta$, também chamado de vida característica que representa o tempo a partir do eixo-x igual a 63,2\% (RELIASOFT, 2004).

Identificados os parâmetros da função é possível então determinar qual estágio o equipamento se encontra na curva da banheira. Por conseguinte, o valor de $\beta$ é de grande importância para se encontrar qual o tipo de manutenção adequada. O Quadro 3 descreve os estágios e os tipos de manutenção para os possíveis valores de $\beta$ (LAFRAIA,2008).

Quadro 3 - Interpretação do parâmetro $\beta$

\begin{tabular}{|l|c|c|}
\hline \multicolumn{1}{|c|}{ VALOR DE $\beta$} & TENDÊNCIA DE TAXA DE FALHAS & TIPO DE MANUTENÇÃO \\
\hline$\beta<1$ & Taxa de falha decrescente & Manutenção Corretiva \\
\hline$\beta=1$ & Taxa de falha Constante & Manutenção preditiva/corretiva/oportunidade* \\
\hline$\beta>1$ & Taxa de falha crescente & Manutenção Preventiva \\
\hline
\end{tabular}

*No Caso de equipamento críticos se justifica o uso de manutenção preventiva. Fonte: LAFRAIA (2008)

Conforme Kardec e Nascif (2001), as principais justificativas para os estágios dos equipamentos, pelo valor encontrado de $\beta$, são analisadas na Figura 3. 
Figura 3 - Diagrama de decisões de um sistema de manutenção

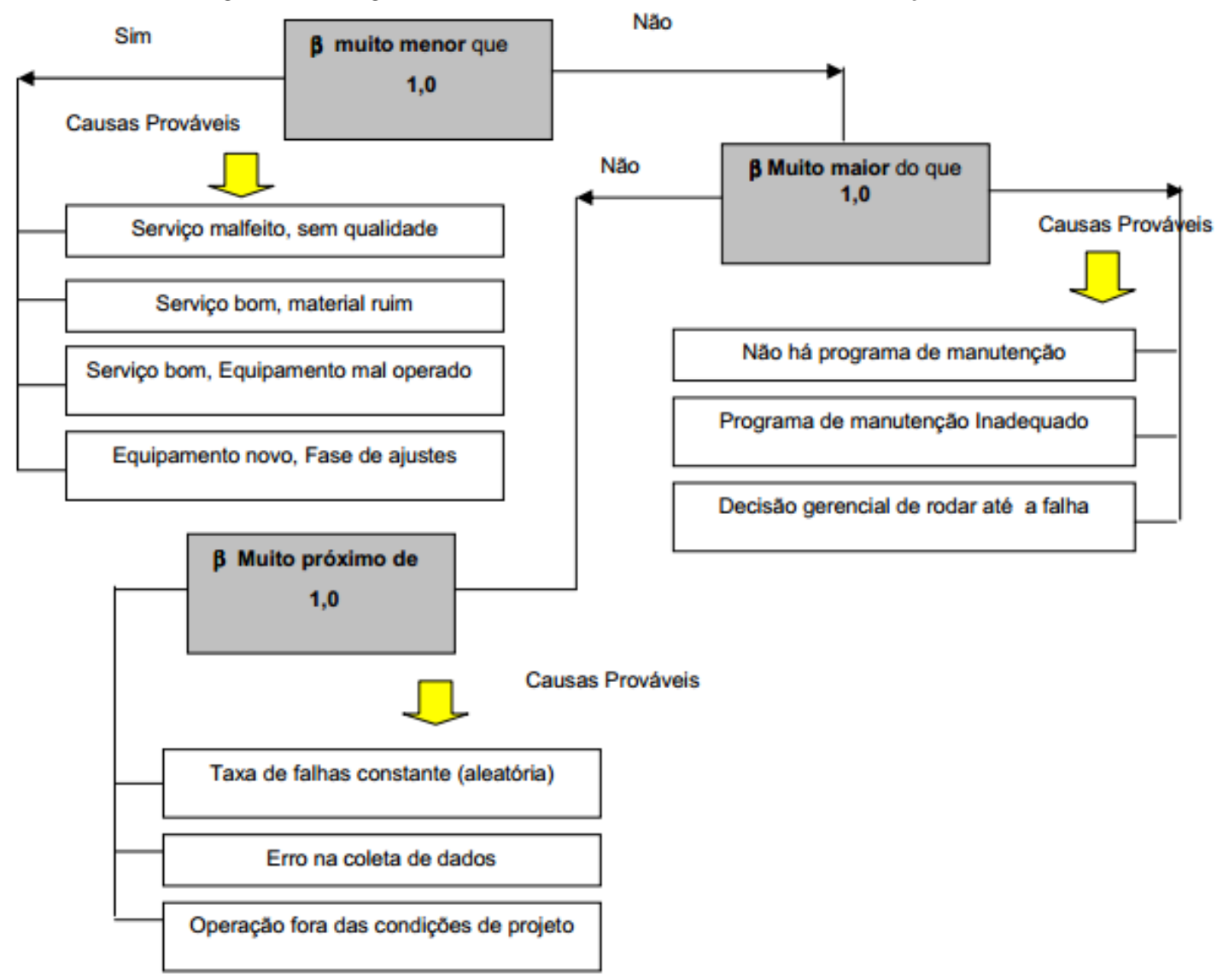

Fonte: Kardec e Nascif(2001)

\section{Metodologia}

Com relação à base metodológica do estudo de caso, este trabalho usou os estudos de Souza (2004), que trabalhou com a otimização do pilar "manutenção planejada" da gestão TPM através da utilização do RCM para nortear as estratégias de manutenção e de Mendes (2011), que trabalhou a manutenção centrada em confiabilidade.

A pesquisa de campo envolveu 12 fases principais, sendo elas:

(i) Optou-se pelo estudo de caso com a empresa Suzano Papel e Celulose (SPC), devido à acessibilidade aos dados do processo. Esta empresa possui duas linhas de produção. Escolheu-se a linha de produção 2, na área de secagem de celulose, mais especificadamente, as três linhas de enfardamento devido ao seu impacto na produção, por ser a etapa final, e por apresentar elevado número de chamados de manutenção.

(ii) A linha de enfardamento da SPC é um processo em lotes, com seções de prensagem, amarração, impressão, dobragem, empilhadora e unitizadora. Os equipamentos selecionados para o estudo neste trabalho foram as prensas, por apresentarem altos tempos de reparo, ocasionando um período maior de linha parada e por serem equipamentos classificados como A, ou seja, são críticos para a produção de fardos de celulose. 
(iii) O levantamento dos tempos de reparo e as datas de início de cada falha, das três prensas foram coletados no sistema de Ordem de Serviços e nos relatórios de turnos feitos pelos operadores e mecânicos, no período de 01/01/2013 à 31/08/2014.

(iv) Foi feita a divisão da prensa em sistemas, subsistema e componentes para identificar a criticidade dos componentes do referido equipamento. Por meio de gráficos de pareto, encontraramse os sistemas que demandaram maior tempo de reparo, ou seja, os que provocaram maior tempo de linha parada. Feito isso, determinou-se, dentro deste sistema, quais foram os componentes responsáveis por essas falhas. Inicialmente a análise ocorreu com os dados das três prensas em conjunto, encontrando o sistema de maior impacto, para então estratificar os levantamentos de falhas para as prensas individualmente.

(v) Identificados os componentes de cada prensa que provocaram maior impacto nas linhas de enfardamento, foi realizada a classificação dos equipamentos quanto ao efeito e criticidade de suas falhas por meio do fluxo de decisão, apresentado no Quadro 1. A classificação é feita conforme os níveis 1, 2 e 3, para os fatores: segurança e ambiente, qualidade, regime de trabalho, produção, frequência e custo. O fluxograma de decisão, Figura 4, tem por finalidade a classificação do componente ou equipamento em classes.

Quadro 4 - Critérios para pontuação do fluxo abc na SPC

\begin{tabular}{|c|c|c|c|}
\hline $\begin{array}{l}\text { FATORES DE } \\
\text { AVALIAÇÃO } \\
\text { A/B/C } \\
\end{array}$ & NÍVEL 1 & NÍVEL 2 & NÍVEL 3 \\
\hline $\begin{array}{l}\text { SEGURANÇA E } \\
\text { AMBIENTE }\end{array}$ & $\begin{array}{l}\text { A falha funcional pode ter } \\
\text { consequências catastróficas em } \\
\text { segurança e saúde ou meio } \\
\text { ambiente. }\end{array}$ & $\begin{array}{l}\text { A falha funcional pode provocar } \\
\text { impactos dentro dos limites legais. } \\
\text { A falha funcional pode provocar } \\
\text { exposição ao risco de acidentes, } \\
\text { respeitando a Política de SSO. }\end{array}$ & $\begin{array}{l}\text { A falha funcional não tem impacto } \\
\text { em Segurança e Saúde ou Meio } \\
\text { Ambiente. }\end{array}$ \\
\hline QUALIDADE & $\begin{array}{l}\text { As falhas funcionais podem ter } \\
\text { consequências catastróficas na } \\
\text { qualidade do produto. }\end{array}$ & $\begin{array}{l}\text { A falha funcional afeta parcialmente } \\
\text { o processo produtivo, podendo } \\
\text { comprometer a quantidade. }\end{array}$ & $\begin{array}{l}\text { A falha funcional não tem impacto } \\
\text { na qualidade do produto. }\end{array}$ \\
\hline $\begin{array}{l}\text { REGIME DE } \\
\text { TRABALAHO }\end{array}$ & $\begin{array}{l}\text { O Equipamento é requerido } 24 \mathrm{~h} \\
\text { por dia. Não existe oportunidade } \\
\text { para manutenções programadas } \\
\text { entre campanhas produtivas. }\end{array}$ & $\begin{array}{l}\text { O equipamento é requerido } 24 \text { horas } \\
\text { por dia, oferecendo algumas } \\
\text { oportunidades para manutenção } \\
\text { programadas entre as campanhas } \\
\text { produtivas. }\end{array}$ & $\begin{array}{l}\text { O equipamento é requerido por } \\
\text { menos de } 12 \text { horas por dia, } \\
\text { oferecendo oportunidades para } \\
\text { manutenções programadas entre as } \\
\text { campanhas produtivas. }\end{array}$ \\
\hline PRODUÇÃO & $\begin{array}{l}\text { A falha funcional do equipamento } \\
\text { causa a interrupção total de linhas } \\
\text { produtivas, podendo provocar } \\
\text { perdas catastróficas de produção. }\end{array}$ & $\begin{array}{l}\text { A falha funcional do equipamento } \\
\text { interrompe de um subsistema ou } \\
\text { sistema, afetando parcialmente a } \\
\text { linha de produção, podendo } \\
\text { provocar perdas de produção ou } \\
\text { aumento no consumo de insumos. }\end{array}$ & $\begin{array}{l}\text { A falha funcional não provoca } \\
\text { perdas de produção e nem provoca } \\
\text { o aumento no consumo de } \\
\text { insumos. }\end{array}$ \\
\hline FREQUÊNCIA & $\begin{array}{l}\text { O histórico demostra ou é } \\
\text { esperado que o equipamento, em } \\
\text { função de características } \\
\text { intrínsecas, apresente falhas } \\
\text { funcionais durante sua vida útil } \\
\text { (mais de uma a cada seis meses). }\end{array}$ & $\begin{array}{l}\text { O histórico demostra ou é esperado } \\
\text { que o equipamento, em função de } \\
\text { características intrínsecas, apresente } \\
\text { falhas funcionais ocasionais durante } \\
\text { sua vida útil (mais de uma a cada } \\
\text { seis a doze meses). }\end{array}$ & $\begin{array}{l}\text { O histórico demostra ou é } \\
\text { esperado que o equipamento, em } \\
\text { função de características } \\
\text { intrínsecas, apresente falhas } \\
\text { funcionais ocasionais pouco } \\
\text { frequentes (menos de uma falha } \\
\text { por ano). }\end{array}$ \\
\hline CUSTO & $\begin{array}{l}\text { O custo de reparo do equipamento } \\
\text { é maior do que } \mathrm{R} \$ 10.000,00 . \mathrm{Na} \\
\text { análise de sistemas ou conjuntos, } \\
\text { considerar a somatória dos valores } \\
\text { de reparo. }\end{array}$ & $\begin{array}{l}\text { O custo de reparo do equipamento é } \\
\text { de } \mathrm{R} \$ 4.000,00 \text { a } \mathrm{R} \$ 10.000,00 . \mathrm{Na} \\
\text { análise de sistemas ou conjuntos, } \\
\text { considerar a somatória dos valores } \\
\text { de reparo. }\end{array}$ & $\begin{array}{l}\text { O custo de reparo do equipamento } \\
\text { é inferior a R } \$ 4.000,00 \text {. Na } \\
\text { análise de sistemas ou conjuntos, } \\
\text { considerar a somatória dos valores } \\
\text { de reparo. }\end{array}$ \\
\hline
\end{tabular}

Fonte: Política de manutenção SPC (2002) 
Figura 4 - Fluxograma atualmente utilizado na SPC

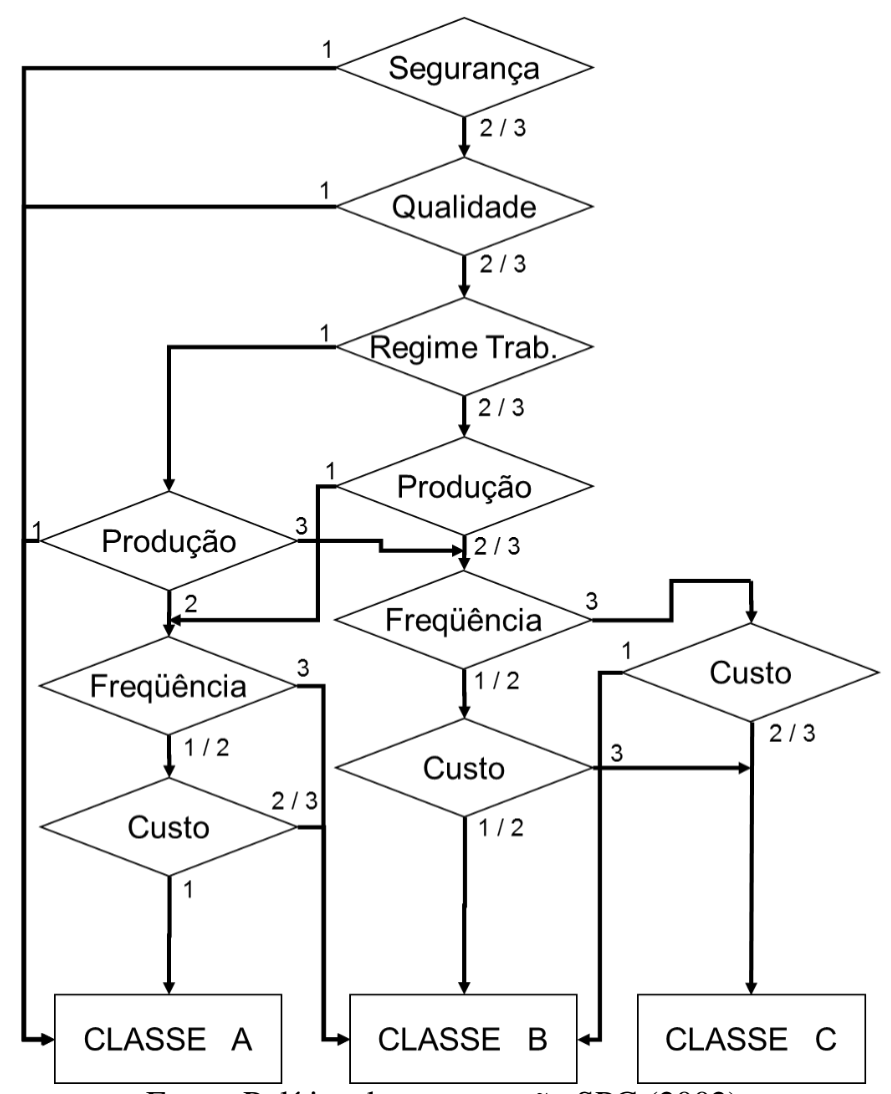

Fonte: Política de manutenção SPC (2002)

(vi) Utilizou-se o modelo de Weibull, por ser o método de distribuições de probabilidade adequado para atingir os objetivos estabelecidos neste trabalho de confiabilidade. Para essa etapa, foi necessário identificar os outlines dos dados de tempo para falha, sendo desconsiderados os tempos abaixo de 24 horas, pois para o engenheiro da secagem, possivelmente tem origem na mesma falha. Para esses valores, somaram-se os tempos de reparo ao dado de falha inicial.

(vii) Para encontrar os parâmetros da função de Weibull, utilizou-se o software Reliasoft Syntheses weibull++ na versão 9 (demo). O programa trabalha com o método de mínimos quadrados.

(viii) Com os parâmetros estabelecidos para cada prensa, descrevem-se as equações de confiabilidade e de probabilidade de acúmulo de falhas como seus respectivos gráficos, feitos pelo software Reliasoft Syntheses weibull++. Por meio das equações, encontrou-se a confiabilidade ao longo de 9 dias de operação de cada prensa.

(ix) Com os valores de $\beta$ (parâmetro da função weibull) foi possível identificar qual estágio, na curva da banheira, o equipamento se encontra. Já o valor de $\eta$, representa a vida característica do equipamento para uma probabilidade de falha de $63,2 \%$.

(x) Calcularam-se os tempos médios de reparo (MTTR), e os tempos médios até falha (MTBF), para as prensas. Para obter valores coerentes e com menor desvio padrão, optou-se 
também por achar o MTTR e MTBF dos componentes críticos. Por meio dessas informações foi possível identificar a disponibilidade do equipamento.

(xi) A partir da determinação da fase em que as prensas se encontram na curva da banheira propõem-se, então, estratégias de manutenção voltadas para esse tipo de frequência de falhas. Para a periodicidade da manutenção, os MTTR, MTBF dos componentes críticos e os valores de confiabilidade das prensas foram considerados.

(xii) Para minimizar o impacto das falhas das prensas nas linhas de enfardamento, aplicaram-se conceitos de outros pilares da TPM.

\section{Estudo de caso}

O estudo de caso foi realizado em uma empresa do setor de papel e celulose. Este setor é caracterizado pelo conjunto de indústrias que abrangem a produção de celulose, de papel e de artefato de papel. A cadeia produtiva deste setor é composta por tais indústrias, juntamente às florestas, indústrias de editoração e gráfica e aos segmentos distribuidores vinculados a essas indústrias (MONTEBELLO, 2010).

\subsection{Caracterização do sistema de produção no setor de papel e celulose}

A descrição do processo produtivo até o produto final, celulose, foi embasado em autores como: Philipp; D'almeida (1988) apud Moraes (2010, p 58), Bittencourt (2004), Piotto (2003), Silva (1994), Lopes (1998), Galdiano (2006) e Wolf (2008). O processo pode ser dividido em linhas de fibras, recuperação, utilidades e máquina de papel, como mostra a Figura 5. Segue as descrições das etapas que fazem parte da linha de fibra, recuperação e máquina de papel. 
Figura 5 - Visão Geral do processo Kraft de produção de celulose

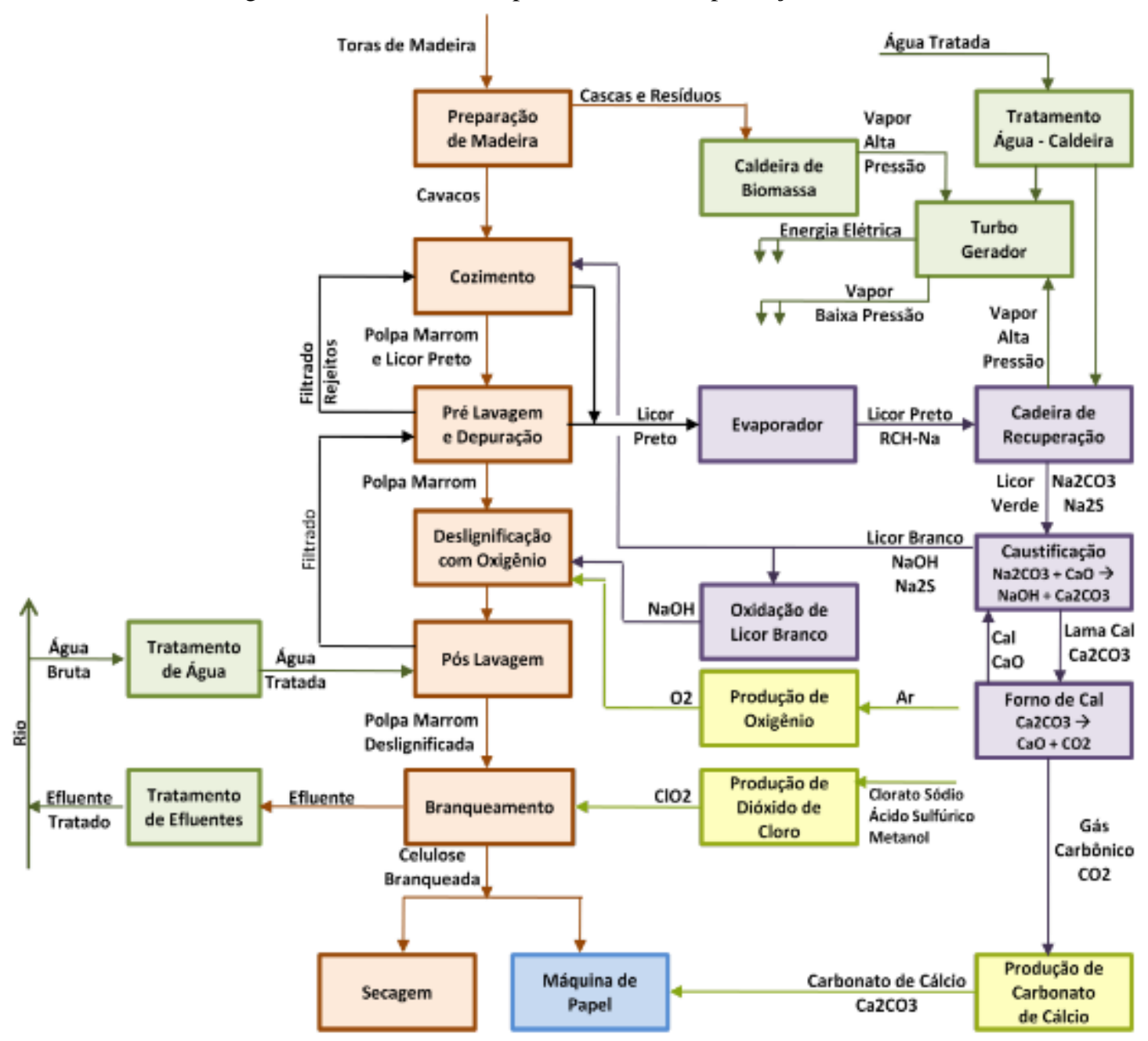

Fonte: Philipp; D'almeida (1988) adaptada por Moraes (2010)

a) Preparação da madeira: Esse setor tem função de receber as toras de madeira, normalmente com 2 a 4 metros de comprimento. $\mathrm{O}$ picador produz cavacos que são encaminhados à pilha de cavacos, que é espécie de estocagem antes do cozimento, chamada de estoque "pulmão";

b) Cozimento: Os cavacos são levados aos digestores, vasos de alta pressão, que por meio da adição do licor branco (sulfeto de sódio e hidróxido de sódio) produzem o desligamento da lignina presente na madeira durante o cozimento. Nessa etapa há a geração da polpa e do licor negro, composto por fragmentos de lignina, celulose degradada, ácidos e sais orgânicos;

c) Recuperação Química: Os evaporadores, a caldeira de recuperação, a caustificação e o forno de cal, fazem parte da etapa de recuperação química que tem o objetivo de recuperar o licor negro transformando-o em licor branco. O destino do licor negro são os evaporadores que o concentra para ser injetado na caldeira de recuperação. A caldeira de recuperação é a queima do licor negro concentrado e sua função é recuperar os reagentes inorgânicos em forma apropriada para reuso, recuperar a energia, em forma de vapor, abater ou eliminar a poluição, tanto do ar como das águas. Desse processo surge o licor verde que segue para a caustificação, onde há adição de óxido de 
cálcio produzindo o licor branco que é bombeando para ser utilizado novamente no digestor. $\mathrm{O}$ subproduto desse processo de recuperação é a lama de cal que será encaminhada para os fornos de cal, onde passará por etapas de secagem, aquecimento e calcinação na qual há a formação de óxido de cálcio, que será reutilizado na etapa de caustificação;

d) Pré-lavagem e Depuração: A lavagem serve para diminuir ao máximo o licor negro da polpa. A depuração é a fase do processo de fabricação da celulose onde as impurezas, tais como palitos e areia, são separadas da celulose nos depuradores, geralmente rotativos, e em separadores centrífugos, respectivamente;

e) Pré-branqueamento e Pós-lavagem: O processo de pré-branqueamento também é chamado de deslignificação e é feito com adição de oxigênio. Essa etapa é considerada muito importante para se definir a qualidade da celulose e do papel que serão produzidos. Quanto menor a quantidade de lignina presente na polpa maior será a economia com produtos químicos no processo de branqueamento e melhor será a qualificação da celulose. Depois dessa etapa, a polpa é encaminhada para uma pós-lavagem que é feita com água limpa;

f) Branqueamento: É a etapa que tem o objetivo de limpar e branquear a polpa através da adição de produtos químicos, como o dióxido de cloro, o ozônio, o peróxido de hidrogênio, o cloro e a soda cáustica. O processo seguinte da produção de celulose é a secagem;

g) Secagem e enfardamento da celulose: Nesta etapa, o objetivo é formação, secagem, corte e embalagem de folhas de polpa de celulose, configurando os fardos de $250 \mathrm{~kg}$ que são transportados pelas linhas de enfardamento para serem unitizados. Como está área foi escolhida para desenvolvimento deste trabalho, ela será detalhada com mais informações.

\subsection{Seleção do sistema e subsistema funcional}

A Suzano Papel e Celulose possui três linhas de enfardamento com capacidade em torno de 3.600 toneladas por dia requerendo a presença de um operador por linha. Depois de formados os fardos na cortadeira, eles são transportados até a prensa onde é feito o controle de peso. Em seguida, eles são transportados para a encapadeira, recebem duas capas e são amarrados na $1^{\mathrm{a}}$ amarradeira com dois arames 2,18mm de espessura, na horizontal. Posteriormente são impressas a identificação do lote e a qualificação da celulose. A próxima etapa é a dobradeira onde o fardo é girado e é feito o “envelope" da capa, para então a $2^{\mathrm{a}}$ amarradeira colocar mais dois arames, agora no sentido vertical. Os fardos seguem então para o empilhador que tem como objetivo empilhar quatro fardos. Quando formam oito fardos, estes seguem para a unitizadora onde são amarrados com arames 3,00mm de espessura e, enfim, são recolhidos pelas empilhadeiras para expedição. A Figura 6 representa o diagrama de blocos das linhas de enfardamentos descritas. 
Figura 6 - Diagrama de blocos das linhas de enfardamento da SPC

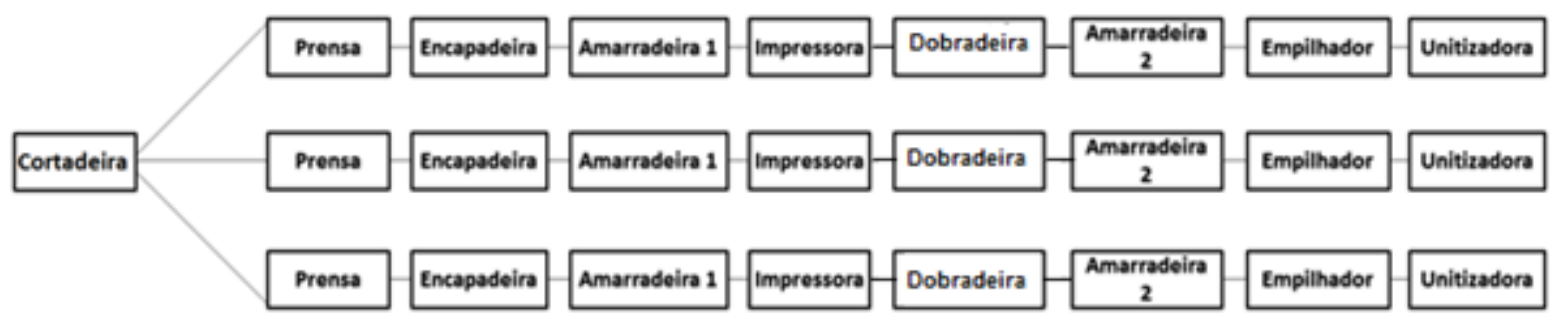

Fonte: Elaborado pelos autores

Para este trabalho foram escolhidas as máquinas RobopressTM, do tipo PR-15 fabricadas pela Metso Paper Sundsvall AB, que podem ser chamadas também de prensa. A máquina foi projetada para prensar fardos de celulose e o período de operação, nas linhas de enfardamento, são de 24 horas por dia.

A prensa foi escolhida por alguns critérios. O primeiro foi por meio da obtenção dos tempos de parada de cada equipamento que compõe as três linhas de enfardamento como pode ser visto nos Gráficos 1, 2 e 3. O segundo critério foi por perceber que a prensa se apresenta como a principal causadora das paradas na linha 3 e em segundo lugar nas linhas 1 e 2, logo atrás da amarradeira. A amarradeira não foi analisada, por ser um equipamento que possui redundância, ou seja, possui equipamento reserva justamente por apresentar muitos problemas referentes à qualidade do arame. Portanto, a seleção da prensa considerou o elevado volume de tarefas de manutenção e o grande número de intervenções corretivas nos últimos anos, que contribuíram para aumentar as paradas da produção.

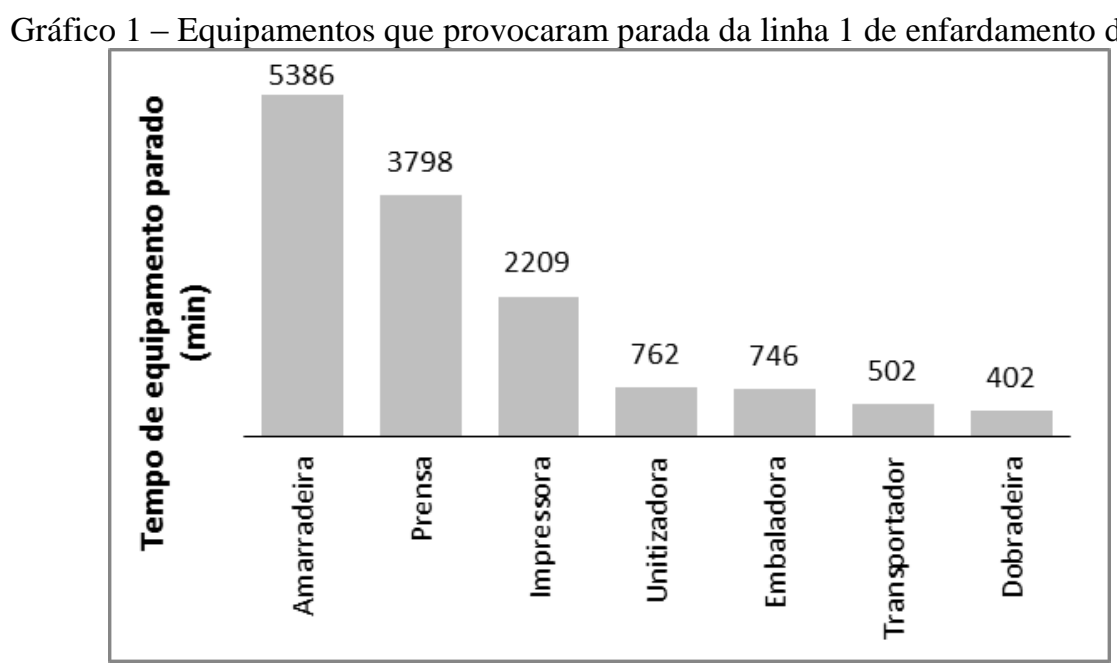

Fonte: Elaborado pelos autores 
Gráfico 2 - Equipamentos que provocaram parada da linha 2 de enfardamento da SPC

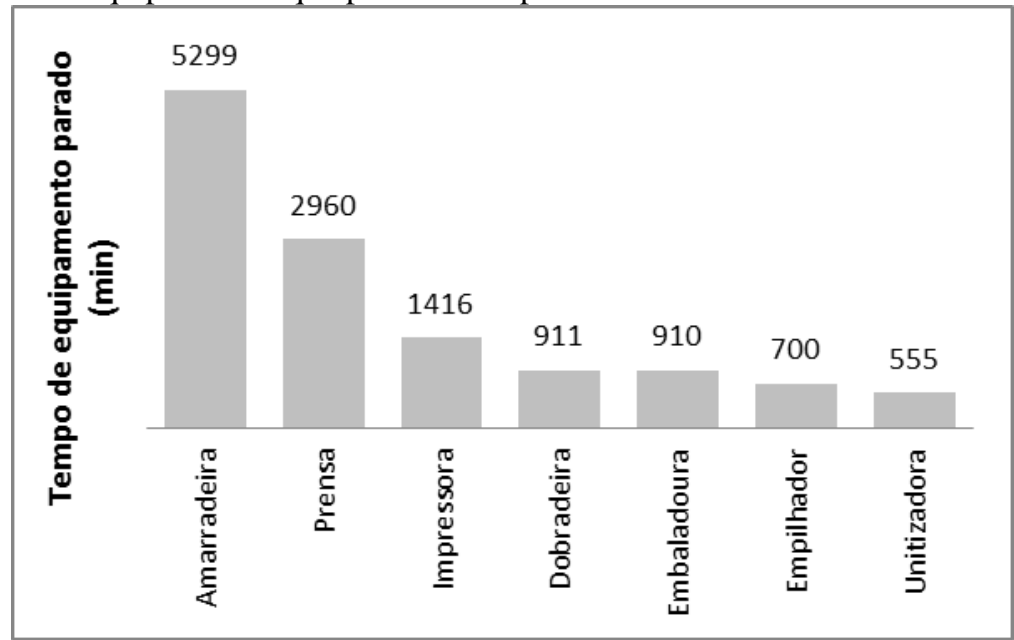

Fonte: Elaborado pelos autores

Gráfico 3 - Equipamentos que provocaram parada da linha 3 de enfardamento da SPC

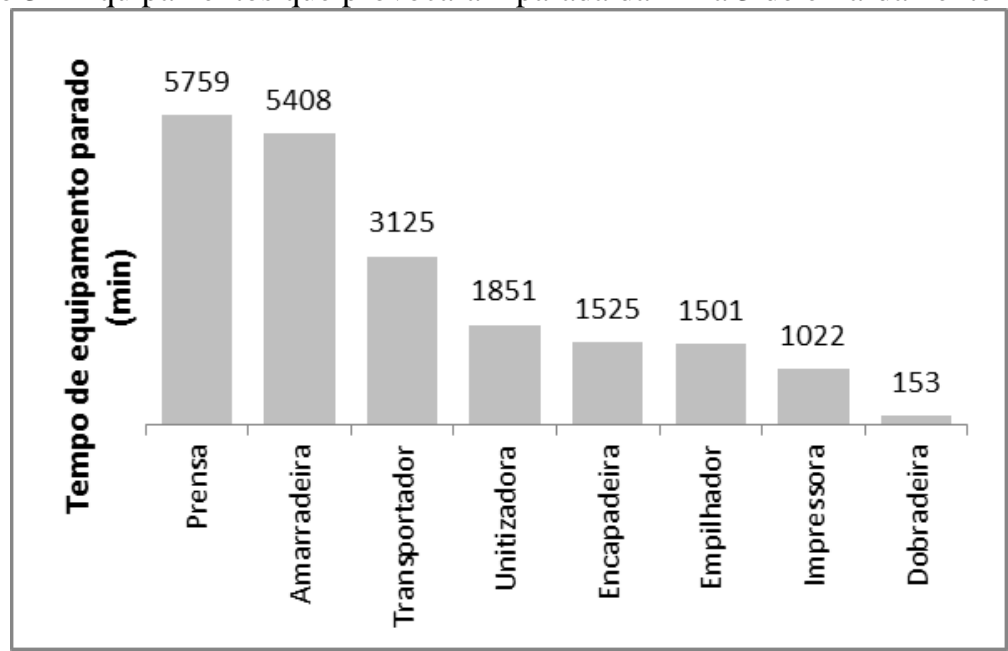

Fonte: Elaborado pelos autores

Vale ressaltar, que o Planejamento da Produção anual de celulose na SPC é baseado no digestor (etapa de cozimento de cavacos), que restringem o desempenho dos sistemas produtivos e se constitui o gargalo da linha 2. Os recursos que, em média, tem capacidade superior à necessária, mas que em função das variabilidades que ocorrem nos sistemas produtivos, podem conjunturalmente apresentar restrições de capacidade são denominados recursos de capacidade restrita (CCR). Este é o exemplo das linhas de enfardamento, em que a prensa, por apresentar constantes problemas com manutenção, acarreta variações na produção ao longo do mês. Portanto, segundo Antunes et al. (2008), os CCRs devem ser geridos visando a eliminação sistemática destas múltiplas fontes de variação, o que pode ser obtido com ações de melhoria e padronização dos métodos de manutenção, visando a aumentar a confiabilidade dos equipamentos. Portanto, a prensa foi o equipamento escolhido para a realização do estudo deste trabalho.

A prensa pode ser dividida em 9 subsistemas que são apresentados no Quadro 5. Para este trabalho, os componentes foram divididos a fim de identificar os que são considerados críticos para a prensa. Entretanto, para se trabalhar com RCM, a prensa foi analisada como um sistema global. 
Quadro 5- Subsistemas e componentes da prensa

\begin{tabular}{|c|c|c|c|}
\hline MÁQUINA & SISTEMA & SUBSISTEMA & COMPONENTES \\
\hline & & \multirow{6}{*}{ Estrutura } & Barra de tensão \\
\hline & & & Travessão superior \\
\hline & & & Fixação do cilindro superior \\
\hline & & & Consolo \\
\hline & & & Barras de guia \\
\hline & & & Travessão inferior \\
\hline & & \multirow{8}{*}{ Transportador } & Motor Trifásico \\
\hline & & & Regulador angular \\
\hline & & & Raspador \\
\hline & & & Rolo Acionador \\
\hline & & & Faixa transportadora \\
\hline & & & Braço de torque \\
\hline & & & Rolo tensor \\
\hline & & & Rolo Externo \\
\hline & \multirow{26}{*}{$\begin{array}{l}\text { Sistema } \\
\text { hidráulico }\end{array}$} & \multirow{4}{*}{ Cilindro principal } & Placa \\
\hline & & & Tubo de enchimento \\
\hline & & & Parafuso de olhai de içamento \\
\hline & & & Êmbolo mergulhador \\
\hline & & \multirow{9}{*}{ Cilindro escravo C6-C7 } & Ligação bomba de arrefecimento \\
\hline & & & Ligação ao cilindro principal \\
\hline & & & Tubo do cilindro $\mathrm{C} 7$ \\
\hline & & & Cilindro hidráulico C6 \\
\hline & & & Ligação de bloco de válvula \\
\hline & & & Êmbolo \\
\hline & & & Faixas de guia \\
\hline & & & Vedação \\
\hline & & & Anel em o \\
\hline & & \multirow{3}{*}{ Bombas } & Bomba M1 \\
\hline & & & Bomba M2 \\
\hline & & & Bomba M3 \\
\hline & & \multirow{2}{*}{ Válvulas } & Válvula de enchimento V30 \\
\hline & & & Válvula principal \\
\hline & & \multirow{3}{*}{ Tanque } & Tanque de óleo \\
\hline & & & Termômetro \\
\hline & & & Transmissor de nível \\
\hline & & \multirow{3}{*}{ Sistema de refrigeração } & Filtro de ar \\
\hline & & & Bomba de circulação \\
\hline & & & Bomba de servo \\
\hline & & \multirow{2}{*}{ Filtro } & Filtro de óleo \\
\hline & & & Filtro de ar \\
\hline & \multirow{15}{*}{ Sistema Elétrico } & \multirow{15}{*}{$\begin{array}{c}\text { Células Fotoelétricas e sensores e } \\
\text { componentes eletrônicos }\end{array}$} & $\mathrm{S} 4$ \\
\hline & & & S5 \\
\hline & & & S6 \\
\hline & & & S7 \\
\hline & & & S8 \\
\hline & & & S9 \\
\hline & & & $\mathrm{S} 10$ \\
\hline & & & $\mathrm{S} 20$ \\
\hline & & & S41 \\
\hline & & & S18 \\
\hline & & & S12 \\
\hline & & & S44 \\
\hline & & & IHM \\
\hline & & & PLC \\
\hline & & & Cartão analógico \\
\hline
\end{tabular}

Fonte: Elaborado pelos autores 


\subsection{Seleção dos subsistemas e equipamentos críticos da prensa}

Nesta etapa, são analisadas as respectivas falhas estruturais dos subsistemas a serem inicialmente abordadas na aplicação do RCM. Inicialmente foi considerada uma análise global usando as informações de tempo de reparo das três prensas, já que são iguais tecnicamente e operacionalmente. A classificação é feita baseada na divisão dos sistemas e subsistemas da prensa. As falhas relacionadas aos fardos de celulose sejam elas: fardo torto e com folhas tortas que ficam com pontas; foram denominadas como falhas operacionais da produção de fardos e não como falhas da prensa. O gráfico 4 mostra que os subsistemas que apresentam maior número de falhas, ou seja, que necessitam de maiores intervenções de reparo de manutenção são o sistema hidráulico e o mecânico. O principal causador das falhas, aproximadamente $51 \%$ dos tempos de reparo, é o sistema hidráulico.

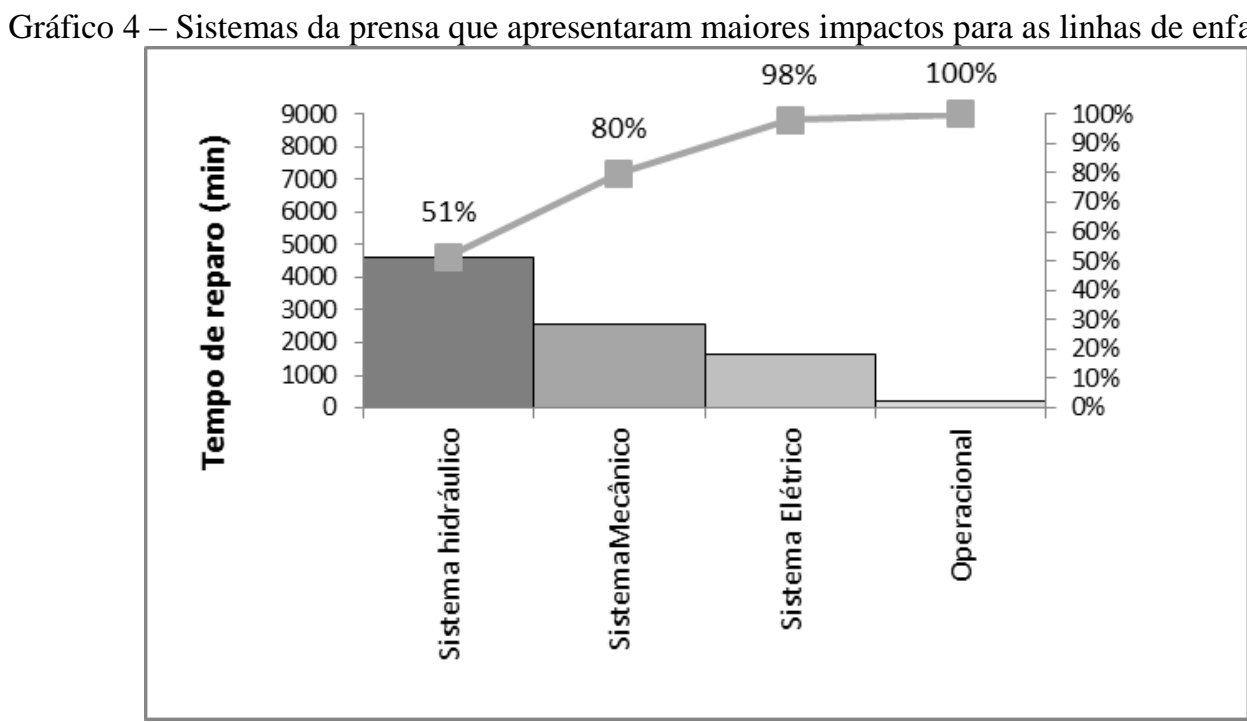

Fonte: Elaborado pelos autores

A utilização da abordagem do RCM em cada prensa de forma individual se fez necessária, para então encontrar os sistemas e os componentes mais críticos. Para isso, buscou-se dentro dos subsistemas, que representam maior impacto para as linhas de enfardamento, quais são os componentes potencialmente críticos para serem analisados no fluxograma de decisões descrito na metodologia.

\subsubsection{Prensa 1}

As estratificações dos impactos das falhas nos subsistemas da prensa 1 são vistas no Gráfico 5. Observa-se que as maiores intervenções de reparo de manutenção foram no sistema hidráulico, com 1.697 minutos de tempo de reparo.

Gráfico 5 - Sistemas da prensa 1 que apresentaram maiores impactos para as linhas de enfardamento 


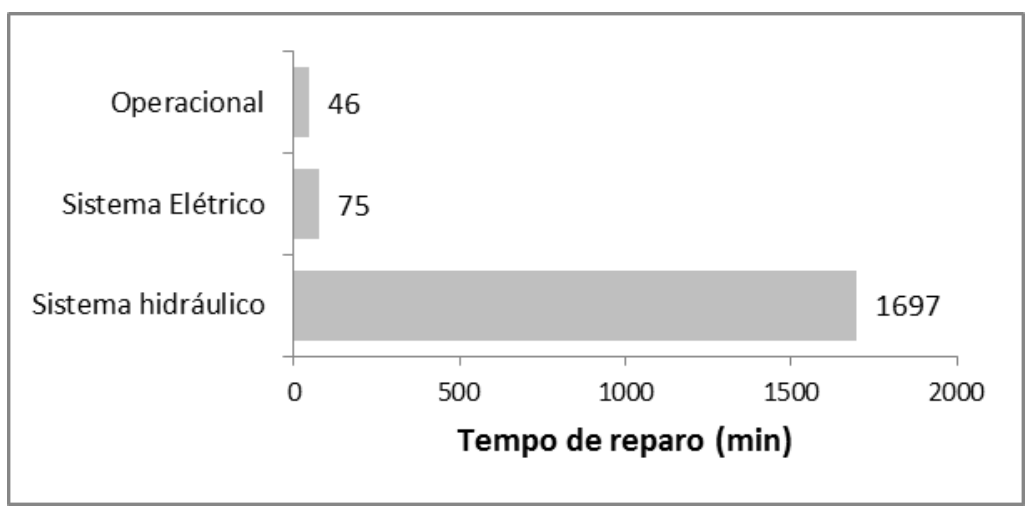

Fonte: Elaborado pelos autores

Para fins de análise de confiabilidade, escolheu-se apenas o sistema hidráulico. Para isso, observou-se que os componentes que afetam o valor de tempo de reparo, na prensa 1, são as bombas M3 e as válvulas. De acordo com o Gráfico 6, a bomba M3, que tem a função de circulação de óleo entre os cilindros auxiliares, escravos e o principal, foi majoritariamente a de maior impacto, porém sua frequência de falhas durante o período estudado foi menor do que as válvulas que representam $28 \%$ das falhas. Por questões de restrição, os componentes da prensa 1 que foram analisados, quanto a sua criticidade e confiabilidade, por meio do software, foram as válvulas. A bomba M3, por apresentar uma quantidade pequena de dados, foi analisada apenas pelo fluxo decisório.

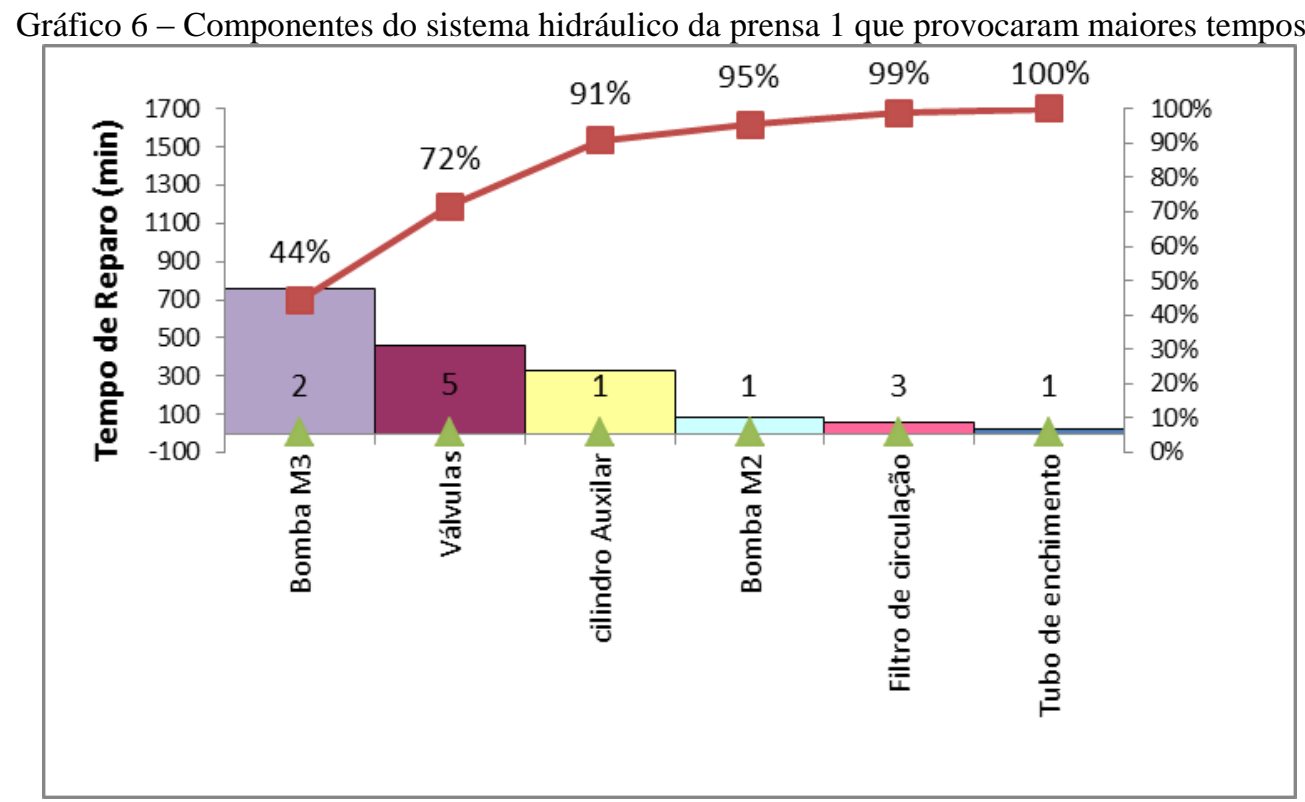

Fonte: Elaborado pelos autores

\subsubsection{Prensa 2}

Para a prensa 2, os subsistemas que apresentaram maior tempo de reparo devido a falhas foram: sistema hidráulico, 809 minutos de reparo e o sistema elétrico com 587 minutos. O Gráfico 7 mostra a participação dos subsistemas na prensa 2. 
Gráfico 7 - Sistemas da prensa 2 que apresentaram maiores impactos para as linhas de enfardamento

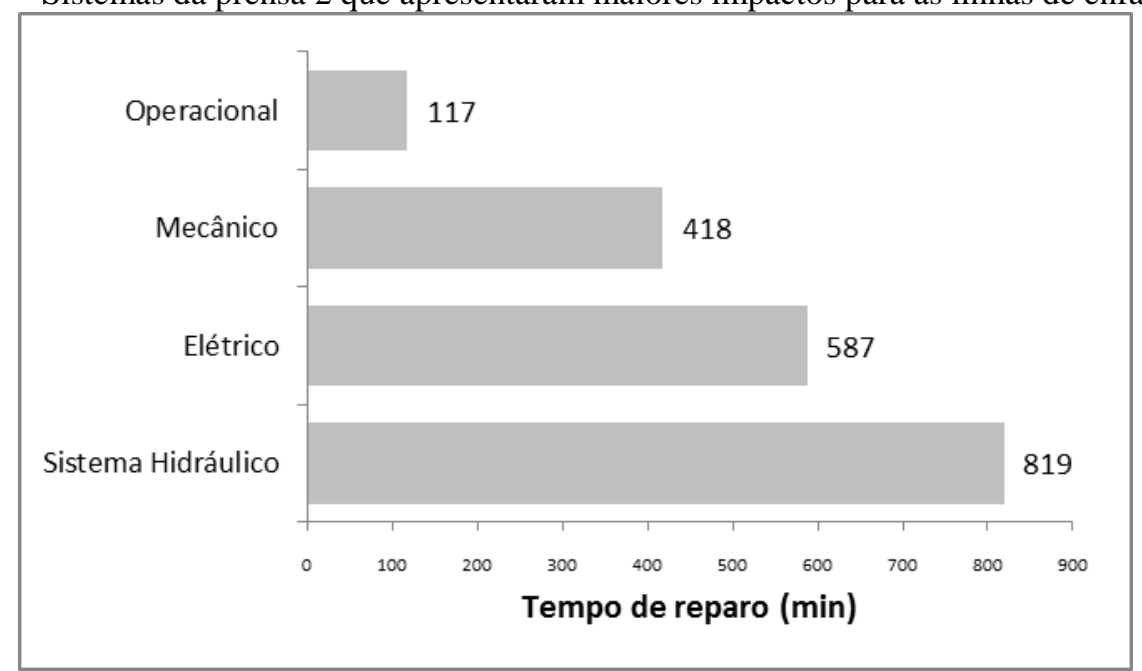

Fonte: Elaborado pelos autores

No sistema de maior representatividade, concluiu-se que as falhas geralmente são provocadas por um ou mais componentes ao mesmo tempo. Isso se deve às lógicas de automação que são estipuladas para o funcionamento da operação e da segurança com portas lógicas. O Gráfico 8 mostra que os sensores S4 e S5, juntos, são os principais itens que provocam falhas no subsistema de células fotoelétricas, sensores e sistema de automação.

Quando o sistema de automação da Prensa 2 apresenta falha de excesso de óleo no cilindro principal, os componentes que são restaurados são os sensores S4 e S5. Portanto, eles são analisados na abordagem do RCM.

Gráfico 8 - Componentes do sistema hidráulico da prensa 2 que provocaram maiores tempos de reparo

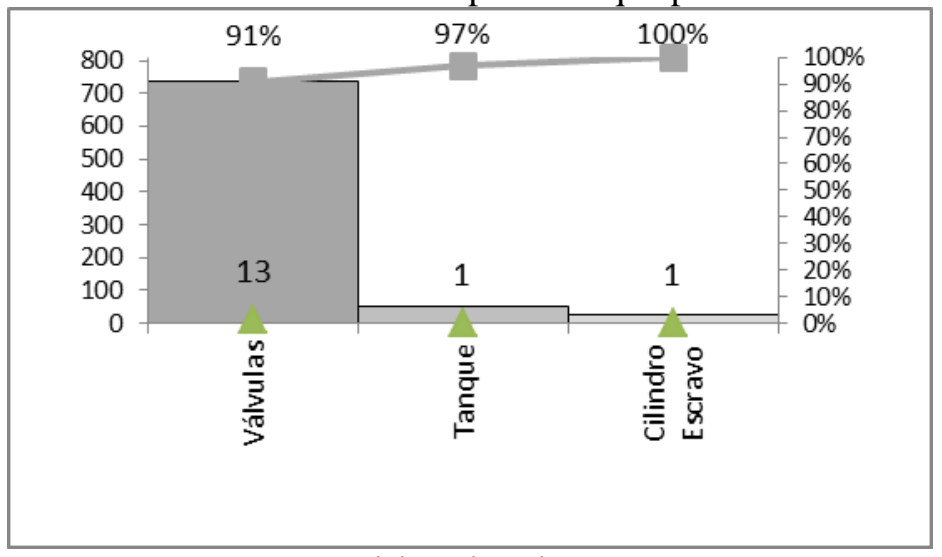

Fonte: Elaborado pelos autores

\subsubsection{Prensa 3}

O sistema da prensa 3 que apresentou grande impacto nos tempos de reparo da linha de enfardamento foi o sistema hidráulico, com 2.789 minutos respectivamente, como mostra o Gráfico 9. 
Gráfico 9 - Sistemas da prensa 3 que apresentaram maiores impactos para as linhas de enfardamento

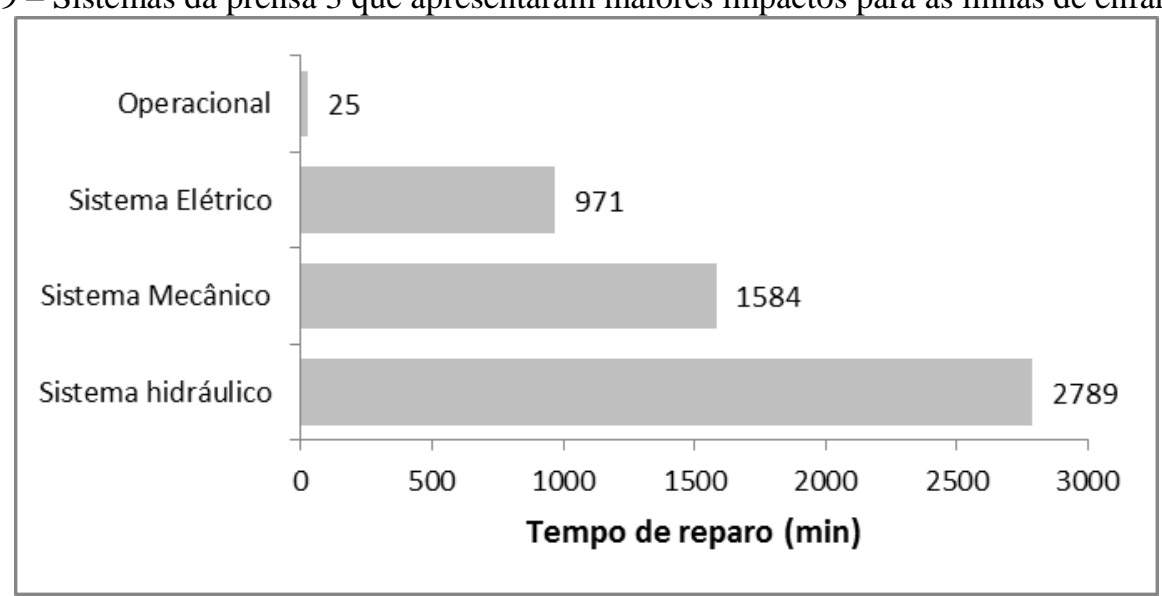

Fonte: Elaborado pelos autores

Estratificando os componentes do sistema hidráulico foi possível perceber que as válvulas prevalecem como o componente que apresentou mais problemas relacionados a reparo na prensa. $\mathrm{O}$ gráfico de Pareto mostra que se forem feitos planos para manutenções preventivas nas válvulas, tem-se uma redução de praticamente $60,1 \%$ das paradas, como exibe o Gráfico 10 . Em vista disto, o item de estudo para os componentes críticos e para a análise de confiabilidade, na prensa 3 , foram as válvulas.

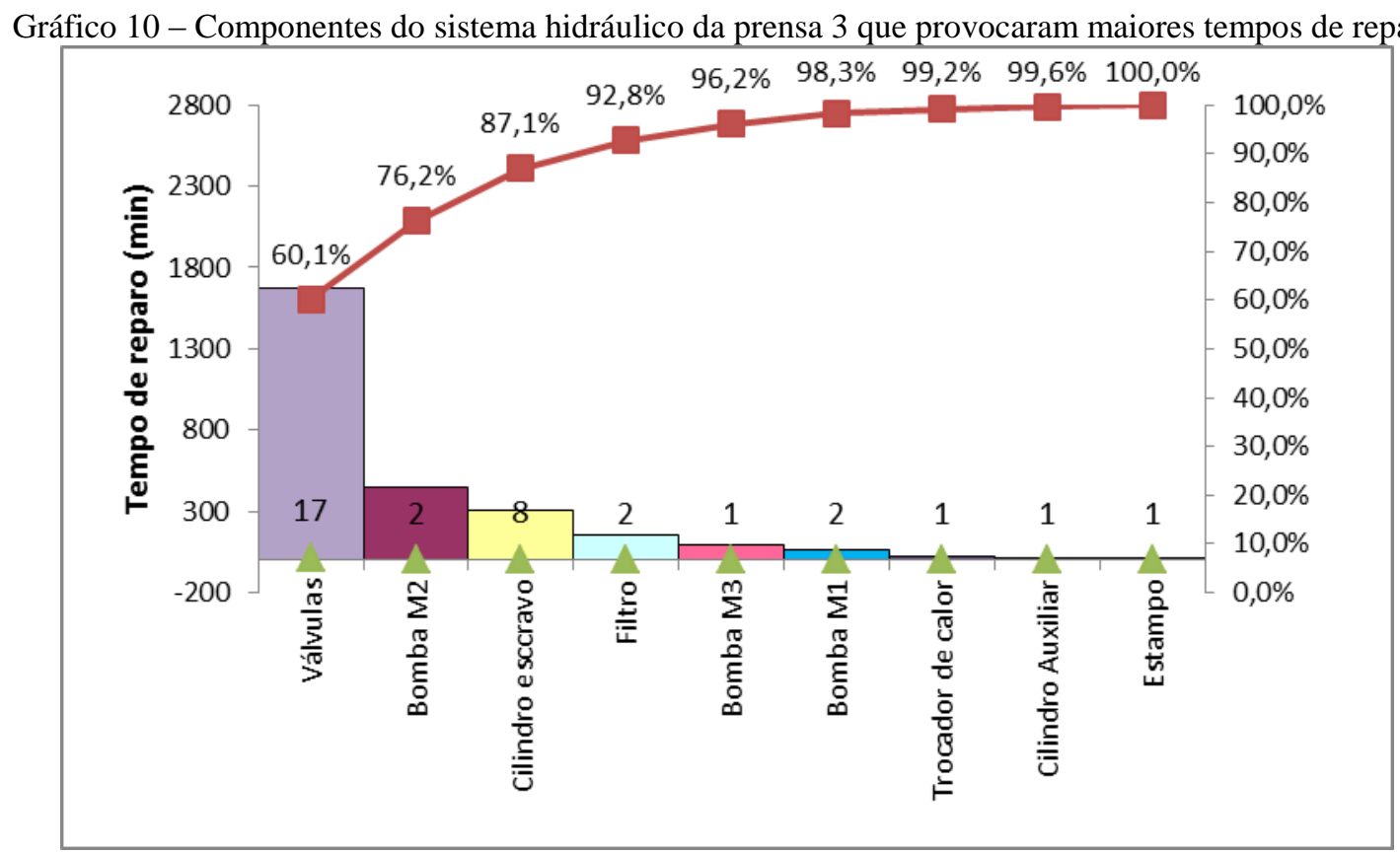

Fonte: Elaborado pelos autores

\subsection{Classificação de criticidade da prensa e seus componentes}

Esta etapa identificou o grau de criticidade e o tipo de manutenção, com relação aos componentes potencialmente críticos identificados na etapa anterior. O sistema foi analisado considerando os seguintes aspectos: (i) segurança; (ii) impacto na qualidade do produto; (iii) regime de trabalho (integral, meio período ou ocasional); (iv) consequência da falha no processo produtivo; 
(v) frequência com que cada falha ocorre; e (vi) custo envolvido no reparo; conforme descrito na metodologia.

As prensas são classificadas como classe A, porém não existe classificação para os seus componentes. As classificações feitas, de forma individual, levaram em conta a criticidade da prensa para a linha de enfardamento, uma vez que a disponibilidade deste equipamento tem afetado a produção de fardos de celulose. Portanto, as análises das prensas foram realizadas juntamente com o responsável pela manutenção da área da Secagem, Suzano/BA. A Tabela 1 mostra o detalhamento de cada componente de acordo com os níveis e categorias, e pelo fluxo decisório demonstrado no Quadro 7, foi possível identificar cada grau de criticidade dos componentes.

Tabela 1-Classificação dos componentes críticos

\begin{tabular}{cccc}
\hline SISTEMA & SUBSISTEMA & COMPONENTE & CLASSIFICAÇÃO \\
\hline Prensa 1 & Sistema hidráulico & Bomba M3 & A \\
Prensa 2 & Válvulas & Válvulas & A \\
Prensa 3 & Sistema hidráulico & Válvulas & A \\
\hline
\end{tabular}

Fonte: Elaborado pelos autores

Dessa análise, conclui-se que tanto as válvulas e as bombas M3 são da classe A. Para as etapas seguintes, as prensas foram analisadas por seus componentes críticos a fim de identificar seu estágio na curva da banheira e qual o tempo em que esse item tem a probabilidade de apresentar $63,2 \%$ das falhas, para então criar planos de ações e análises para os componentes críticos.

\subsection{Função de confiabilidade}

Apartir dos dados de tempos para falhas foi possível identificar os parâmetros para a função de confiabilidade utilizando a função de probabilidade weibull. Com os valores dos parâmetros $\beta$ e $\eta$, foi possível encontrar as equações de confiabilidade e de probabilidade de falha. $\mathrm{O} \beta$ indica em qual estágio da curva da banheira as prensas se encontram e qual seria a estratégia ideal de manutenção para os seus tipos de falhas. Já o parâmetro $\eta$, significa o tempo provável em que 63,2\% das falhas já ocorreram.

Os dados de tempos para falhas das prensa 1, 2 e 3, foram trabalhados pelo software Reliasoft Syntheses weibull ++ e obtiveram-se os parâmetros de $\beta$ e $\eta$ para a função de confiabilidade e de probabilidade de falhas acumuladas. Definiram-se algumas configurações de análise do software, para que este realize suas funções baseadas em regressão linear e aproximações median Ranks. Obtiveram-se os parâmetros para a equação confiabilidade, para as prensas, descritas na Tabela 2. Para o caso estudado, estas expressões foram computadas numericamente pelo software Reliatsoft Weibull ++ , fornecendo tanto $\mathrm{C}(\mathrm{t})$ quanto $\mathrm{F}(\mathrm{t})$ para cada prensa, com os seus devidos parâmetros encontrados, conforme Tabela 1. 
Tabela 2 - Equações de probabilidade de acúmulo de falhas e de confiabilidade para as três prensas

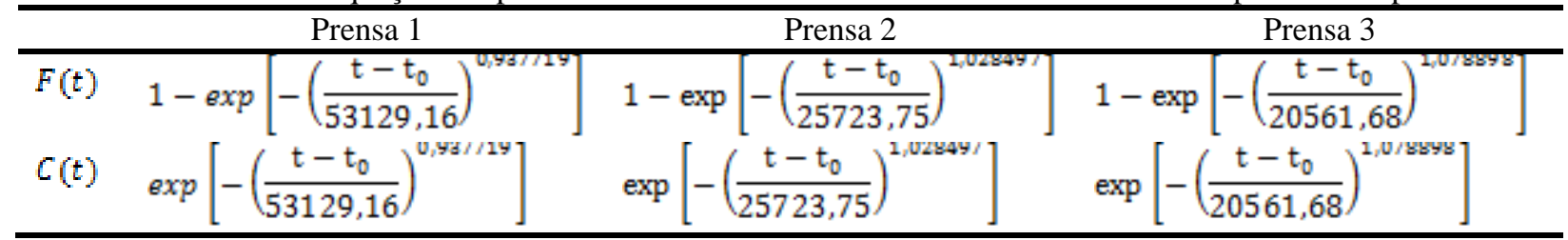

Fonte: Elaborado pelos autores

Para auxiliar o entendimento, a Tabela 3 representa os valores de confiabilidade das prensas ao longo do tempo (t). Pode-se observar que a prensa 1, ao final de 9 dias, apresenta um valor provável de confiabilidade melhor do que as outras duas prensas. A confiabilidade garantida, que é definida com o padrão de 0,85 , acontece até o dia 5 , até o dia 3 e até o dia 2 , para as três prensas respectivamente. Passado este período, o valor da confiabilidade de cada prensa é inferior ao padrão sugerido. Um fato importante são as diferenças de confiabilidade das três prensas, que podem ser justificadas por estarem na fase de falhas aleatórias, da curva da banheira.

Tabela 3- Valores de confiabilidade para as prensas com o tempo

\begin{tabular}{cccccccccc}
\hline \multicolumn{10}{c}{$\mathrm{C}(\mathrm{t})$} \\
\hline $\mathrm{t})$ & 1 dia & 2 dias & 3 dias & 4 dias & 5 dias & 6 dias & 7 dias & 8 dias & 9 dias \\
Prensa1 & 0,97 & 0,94 & 0,91 & 0,88 & 0,86 & 0,83 & 0,81 & 0,79 & 0,77 \\
Prensa2 & 0,95 & 0,90 & 0,85 & 0,81 & 0,76 & 0,72 & 0,68 & 0,65 & 0,61 \\
Prensa 3 & 0,94 & 0,89 & 0,83 & 0,78 & 0,72 & 0,67 & 0,63 & 0,59 & 0,54 \\
\hline
\end{tabular}

Fonte: Elaborado pelos autores

\subsection{Análise das prensas}

As prensas começaram a operar em 2006, desde então, a empresa Suzano papel e celulose teve vários cenários de produção. Desde 2011 considera-se a área da secagem como estável em termos de operação. As três prensas apresentaram um $\beta$ muito próximo de 1 . Isso mostra que as funções de densidade de probabilidade de falhas apresentam frequências constantes. Portanto, as prensas se encontram na fase de maturidade da curva da banheira ou período de vida útil. Nesta fase, as falhas ocorrem por causas aleatórias, que podem ser por interferência indevida, tensão e deficiência, fator de segurança insuficiente, ocorrência aleatória de cargas acima do esperado, resistência menor que a esperada, defeitos abaixo do limite de sensibilidade dos ensaios que acabam escapando às inspeções, erros humanos no uso ou instalação do produto, operação indevida, falhas não detectáveis por testes, fenômenos naturais imprevisíveis, causas sem explicação definida (CHAVES NETO, 2005).

Para Kardec e Nascif (2001), uma das várias causas prováveis para justificar o valor do parâmetro $\beta$ próximo de 1 , é o fato do equipamento operar fora dos padrões de projeto. $\mathrm{O}$ tipo de estratégia de manutenção a ser adotada pode ser manutenção preditiva, corretiva ou manutenção preventiva, caso o impacto da falha tenha reflexos na produção (LAFRAIA, 2008). 
A prensa é considerada como um sistema complexo. Atualmente a empresa trabalha com planos de manutenção denominados de preventivos, tanto para parte hidráulica mecânica e elétrica. Porém, eles são apenas checklists para verificação dos componentes. Caso os inspetores ou mecânicos encontrem alguma peça danificada, faz-se o planejamento para uma corretiva planejada.

Outro ponto a ser destacado são os altos tempos de reparo das prensas. Quando ocorre uma falha, que faz a prensa parar, a equipe de manutenção atua de forma corretiva para encontrar o defeito, para enfim conseguir resolvê-lo. Isso se traduz nos indicadores de tempo médio entre falhas (MTBF) e no tempo médio de reparo (MTTR). Os seus valores são vistos na Tabela 4.

Tabela 4 - Valores de MTBF e MTTR das prensas

\begin{tabular}{lcccc}
\hline & MTBF (horas) & MTTF (horas) & MTTR em 1 mês (horas) & $\begin{array}{c}\text { DISPONIBILIDADE (1 } \\
\text { mês) }\end{array}$ \\
\hline Prensa 1 & 1168,99 & 1,89 & 1,16 & $99,67 \%$ \\
Prensa 2 & 423,61 & 1,05 & 1,76 & $99,75 \%$ \\
Prensa 3 & 332,84 & 2,13 & 4,60 & $99,35 \%$ \\
\hline
\end{tabular}

Fonte: Elaborado pelos autores

Utilizando a Equação 4, obtém-se a disponibilidade das três prensas estudadas. Pode-se então dizer que em 99,35\%, 99,67\% e 99,75\% do tempo, os equipamentos estiveram disponíveis para a operação. Em ordem crescente esses valores representam as prensas 3, 1 e 2 respectivamente. Quanto ao valor da disponibilidade, observa-se que este depende da estratégia de manutenção, pois esta afeta o intervalo entre falhas, pela quantidade de preventivas realizadas, e o tempo até o reparo, pelos recursos humanos, ferramentais e peças-reserva.

Os valores de MTBF são coerentes com os encontrados pela equação de confiabilidade, pois a prensa que tem o período maior entre falhas é a prensa 1, ou seja, a maior probabilidade de não apresentar falhas se comparada as três linhas. Porém, quando se trabalha confiabilidade deve-se identificar o MTTR. Se projetado para um mês, percebe-se que a prensa três demandará mais tempo de linha parada para intervenção da manutenção. Contudo por envolver todos os sistemas das prensas, esses valores podem não condizer com a realidade, pois apresentam desvio padrão alto, uma vez que o reparo para limpeza de um sensor é bem menor que o reparo em uma válvula.

Os componentes críticos identificados possuem tempos característicos de reparo, logo a estratificação em componentes para se calcular o MTTR se fez necessária. Os componentesque demandaram mais tempo de reparo, se caracterizando como os críticos para as prensas foram: bomba M3 e as válvulas. Os seus tempos médios são vistos na Tabela 5 e os valores de tempo médio até falha são observados na Tabela 6. 


\begin{tabular}{lcc}
\hline & MTTR (horas) & Válvulas \\
\hline & Bomba M3 & 1,58 \\
Prensa 1 & 6,22 & 2,28 \\
Prensa 2 & & 3,21 \\
Prensa 3 & & \\
\hline
\end{tabular}

Fonte: Elaborado pelos autores

Tabela 6 - Valores do MTBF das prensas

\begin{tabular}{lcc}
\multicolumn{3}{c}{ Tabela 6 - Valores do MTBF das prensas } \\
\hline & MTBF (dias) & Válvulas \\
Prensa 1 & Bomba M3 & 136,89 \\
Prensa 2 & 115,04 & 35,22 \\
Prensa 3 & & 36,05 \\
\hline
\end{tabular}

Fonte: Elaborado pelos autores

Conhecendo o MTTR e a confiabilidade da prensa é possível criar planos de manutenção preditiva e preventiva para os modos de falhas dos componentes críticos. Para isso, é necessário melhor compreensão do funcionamento e reparo da prensa, pois as falhas que ocorreram no período estudado estão associadas a defeitos aleatórios (fase de vida útil).

Os principais modos de falhas envolvendo válvulas se devem a um desequilíbrio no sistema dinâmico de óleo da prensa, uma vez que a válvula de enchimento permite encher rapidamente o cilindro principal durante o movimento descendente/pré-prensagem e esvaziá-lo durante o movimento de retorno abrindo uma ligação direta entre o cilindro principal e escravo, que possuem volumes, para o armazenamento de óleo, diferentes. Portanto, se os sensores S4 e S5 perceberem qualquer desnível de óleo ele apresenta a falha de excesso de óleo no cilindro principal ou falta de óleo no cilindro principal. Logo, as ações para esse modo de falha seria relacionadas à manutenção preditiva com periodicidade estabelecida conforme o MTBF do componente, que foi de aproximadamente 140, 35, 35 dias para as três prensas respectivamente.

A manutenção preditiva é indicada por fazer o monitoramento e o acompanhamento dos tipos de desempenho do equipamento, no caso das válvulas, por meio de instrumentos que fornecem dados quantitativos do componente. Esse tipo de manutenção mostra as condições reais do funcionamento das máquinas com base em dados que informam seus desgastes ou processo de degradação. Além da manutenção preditiva nas válvulas é importante realizar a preventiva com troca e calibração dos sensores, como também os seus cabos.

Já a Bomba M3, é a bomba principal para o sistema hidráulico, ela é a responsável pela circulação do óleo entre as bombas M1 e M2. Por isso, caso ela apresente falha, a prensa é intertravada deixando de operar. As falhas são geralmente relacionadas a vazamentos de óleo. Logo, os mangotes e vedações desse componente devem ter um plano de troca baseado no seu MTBF, tanto para prensa 1, quanto para a 2 e a 3. Seu tempo médio de reparo, de aproximadamente 112 dias, é alto e pode provocar uma perda de produção equivalente à 877 TSA. 
Não se pode generalizar o resultado obtido. O máximo que se pode esperar, por repetição de casos de falhas, é o aperfeiçoamento do método para prevenção e reparo com base na filosofia da TPM, sempre que novas aplicações aportem aleatoriamente. Por isso, o controle deve incluir a teoria e a prática dos procedimentos de análises de falhas para se obter um MTBF e um MTTR menor.

Outros modos de falha frequente envolvendo a prensa são os vazamentos de óleo. Esses afetam a confiabilidade do equipamento como um todo. Por isso, os vazamentos internos na prensa e nos cilindros escravos, devem ter como estratégia de manutenção a preditiva, por meio do acompanhamento da temperatura do cilindro. Essa variável de temperatura define qual cilindro deverá ter suas vedações e selos trocados que deverão ser planejados para troca a cada parada programada de linha de enfardamento, dentro de duas semanas.

\subsection{Plano de manutenção}

A última etapa do processo RCM é a formulação e implantação do plano de manutenção. Para tanto, deve-se associar a cada item físico, considerado crítico, às tarefas de manutenção recomendadas para os modos de falha descritos na etapa anterior. O plano contempla ainda a frequência de realização das tarefas.

Com base na TPM, a maximização do desempenho operacional das máquinas e equipamentos como também o acompanhamento do ciclo de vida útil da máquina e do equipamento são importantes. A empresa possui um banco de dados, fornecido pelo fabricante das prensas, sobre as principais ações para os modos de falhas durante a sua fase de maturidade. Esse banco de dados é chamado de troubleshotting. Porém, como o quadro de funcionários foi recentemente renovado, torna-se necessário reorientar todos os funcionários.

Essas ações direcionam a equipe de manutenção para a correção das falhas. Isso se caracteriza como um método para a diminuição do tempo de reparo em casos de manutenção corretiva não programada. A periodicidade e o tipo de manutenção podem ser ajustados. E o novo plano de manutenção pode aproveitar várias ferramentas da gestão TPM, como a elaboração de uma matriz de habilidades e conhecimentos para a identificação dos gaps, ou lacunas, de conhecimentos e habilidades da equipe de trabalho. Esses gaps podem ser reduzidos ou eliminados por meio da execução de planos de treinamento específicos e/ou confecção de LPPs (Lições Ponto a Ponto) pelos manutentores e operadores. As LPPs, geralmente, são utilizadas para transmissão de um conhecimento pontual para toda a equipe através de um desenho num formulário de dimensão aproximadamente de $1 \mathrm{~m}^{2}$. Através dessas ferramentas de treinamento algumas atividades simples e importantes para o funcionamento das máquinas podem ser transferidas dos manutentores para a operação. 
Além disso, os planos de manutenção devem receber ações oriundas das análises de falhas dos equipamentos. A execução dessas ações impede a recorrência das falhas através de melhorias nos procedimentos ou nos componentes mecânicos das máquinas.Vale ressaltar que a implementação da estrutura de manutenção planejada, da TPM, se estabelece em 7 etapas. São elas: avaliar o equipamento e compreender a situação atual, trazer os equipamentos as condições originais, criar um sistema de gestão das informações, estruturação da manutenção periódica, estruturação da manutenção baseada na condição, avaliação do aumento da confiabilidade, manutenibilidade e otimização da manutenção e nos custos e por fim a etapa de utilizar o equipamento no limite.

\section{Considerações finais}

A TPM e a RCM são complementares, ou seja, as ferramentas da RCM podem está inseridas na gestão do Pilar de Manutenção Planejada para definir a melhor estratégia de manutenção a ser adotada. Este trabalho teve como objetivo encontrar as melhores estratégias de manutenção, por meio da aplicação da RCM, em um estudo de caso na Suzano Papel e Celulose. Escolheu-se como área a secagem da MC2, e como sistema as prensas de fardo de celulose, que são recursos com capacidade restrita, que vem provocando elevados tempos de parada de linha, por apresentarem planos de manutenção inadequados para a taxa de falhas em que atualmente se encontram falhas aleatórias.

Os objetivos propostos foram atendidos e com isso identificou-se a importância de reduzir os tempos de reparos nos principais componentes da prensa utilizando, como meio, as atividades de treinamento e educação da equipe de manutenção e produção, como também a participação conjunta dos operadores do equipamento na atuação de pequenas atividades como limpeza de sensores e acompanhamento de alarmes de falhas.

Os CCRs, diferentemente dos gargalos, são recursos que, em média, têm capacidade superior à necessária para atender uma determinada demanda. Porém, dado as variabilidades nos sistemas produtivos, podem conjunturalmente apresentar restrição de capacidade, que acarretam em grandes impactos no desempenho do sistema produtivo. Portanto, estabelecendo a estratégia ideal e as periodicidades de manutenção, consegue-se minimizar e eliminar as principais fontes de variação do sistema escolhido, que eram os excessos de manutenções corretivas.

Verificaram-se, neste trabalho algumas dificuldades, como a estratificação dos dados de falhas, que são registradas por turno, ou seja, se o tempo de reparo fica entre dois turnos, no sistema são registradas duas falhas, sendo que se tratam de uma mesma falha, até mesmo falhas com pequenos períodos de intervalo, que levavam aos valores errôneos dos parâmetros para a função de probabilidade Weibull. Outra dificuldade foi identificar por meio das descrições de falhas, contidas 
no sistema da empresa, as divisões de subsistema e componentes, já que não existe um padrão de preenchimento, por serem 5 turnos de trabalho diferentes, que se alternam durante a semana. Além do mais os relatórios no OCR não definem a origem da falha por componente.

Para trabalhos futuros seria indicado o desenvolvimento de análise dos custos de manutenção para determinar a eficácia do RCM, comparando-as com o ganho que a empresa deixa de obter por não adotar as estratégias de manutenções adequadas.

Como pode ser visto a busca pela maximização da eficiência das máquinas exige um trabalho contínuo e permanente de todas as áreas envolvidas. É necessário que a Manutenção Planejada esteja integrada às demais áreas da empresa. A chave para o sucesso da implantação das metodologias TPM e RCM é a participação atuante de todos os envolvidos suportados pela liderança da empresa.

\begin{abstract}
The reliability of equipment or systems is a major concern in maintenance management. It provides higher availability and equipment life, which translates into financial gains for the organization, especially when the machine is considered a bottleneck or a resource with limited capacity (CCRs). This paper deals with the application of Reliability Centered Maintenance (RCM) as a way of finding the best pillar of the maintenance strategy "planned maintenance" of Total Productive Maintenance (TPM). The case study was done on the presses of pulp bales of baling lines of Suzano Papel e Celulose (SPC). Currently, the press is a CCR, i.e., have higher capacity than needed, but depending on the variability that occur in productive systems, can circumstantially present capacity constraints. Due to the high numbers of so-called maintenance, which require large line downtime, the company has had production losses. To find the best maintenance strategy for presses, its reliability was obtained with the help of the Software ReliasoftWeibull ++, identifying the presses are at the stage of random failures, of the bathtub curve. For their critical components, which are valves and pump M3, the average time to failure (MTBF) and mean time to repair his (MTTR) rose, and then set guidelines for press maintenance plan based on the TPM activities of the pillars.
\end{abstract}

Key-words: maintenance management; reliability of equipment; TPM activities.

\title{
Referências
}

ANTUNES, J. et al. Sistemas de Produção: conceitos e práticas para projeto e gestão da produção enxuta. São Paulo: Bookman Editora, 2008.

ASSOCIAÇÃO BRASILEIRA DE NORMAS TÉCNICAS. NBR 5462: confiabilidade e mantenabilidade. Rio de Janeiro: ABNT, 1994.

BERGAMO, V. Confiabilidade: básica e prática. Edgard Blücher Ltda.: São Paulo,1997. 108p.

BIASOTTO, E. Aplicação do BSC na gestão da TPM: estudo de caso em indústria de processo. 2006.170 p. Tese (Mestrado em Engenharia Mecânica). Programa de Pós-Graduação em Engenharia Mecânica. Universidade Federal de Santa Catarina, Florianópolis, 2006.

BITTENCOURT, E.Parâmetros de otimização no processo de fabricação de celulose e papel. 2004.76 p. Tese (Mestrado em Ciências Agrárias) - Programa de Pós-Graduação em Engenharia Florestal, Universidade Federal do Paraná, Paraná, 2004.

BLOOM, N. B. Reliability Centered Maintenance: implementation made simple. New York: McGraw-Hill, 2006.

BRANCO FILHO. G. Dicionário de termos de manutenção e confiabilidade. Rio de Janeiro: Ciência Moderna, 2000. 
CHAVES NETO; A. Confiabilidade e métodos estatísticos aplicados a sistemas de engenharia. Curitiba, 2005. Apostila digitada.

CHIAVENATO, I. Gestão de pessoas: o novo papel dos recursos humanos nas organizações. Rio de Janeiro: Campus, 1999. $524 \mathrm{p}$.

DESHPANDE, V.S.; MODAK, J.P. Application of RCM for safety considerations in a steel plant. Reliability Engineering and System Safety. Vol. 78, p. 325-334, 2002. crossref

ELSAYED, E. A. Reliability engineering. Reading, MA: Addison Wesley Longman, 1996. 737p.

FALCETTA, E. F. Análise da confiabilidade de produtos baseada em dados de utilização da garantia. 2000. Dissertação (Mestrado em Engenharia de Produção) - Programa de Pós-Graduação em Engenharia de Produção, Universidade Federal do Rio Grande do Sul, Porto Alegre, 2000.

FOGLIATTO, F. S.; RIBEIRO, J. L. D. Confiabilidade e Manutenção Industrial. São Paulo: Campus; Elsevier, 2011.

GALDIANO, G. P. Inventário do ciclo de vida do papel offset produzido no Brasil. 2006. 303 p. Tese (Mestrado em Engenharia) - Programa de Pós-Graduação em Engenharia Química, Universidade de São Paulo, São Paulo, 2006.

GITS, C.W. Design of maintenance concepts. International Journal of Production Economics, Eindhoven, v. 24, p. 217-226. 1992. crossref

GERAGHETY, T. Obtendo Efetividade do Custo de Manutenção Através da Integração das Técnicas de Monitoramento de Condição, RCM e TPM. Maintenance Magazine, São Paulo, vol. 11, no 1, p. 97-100.

HANSEN, R.C. Eficiência global dos equipamentos: uma poderosa ferramenta de produção/manutenção para o aumento dos lucros. Porto Alegre: Bookman. 2006.

KARDEC, A.; NASIF, J. Manutenção: função estratégica. Rio de Janeiro: Qualitymark, 2001. 287p.

KELLY, A. Maintenance strategy: business-centred maintenance. Elsevier science Ltda.:Oxford, 2002.

LAFRAIA, J. R. B. Manual de confiabilidade, mantenabilidade e disponibilidade. Rio de Janeiro: Qualitymark, 2008.

LOPES, C. R. A. Análise da indústria de papel e celulose no Brasil. 1998. 142 p. Tese (Mestrado em Adminstração) - Programa de Pós-Graduação em Administração, Universidade Federal do rio de Janeiro, Rio de Janeiro, 1998.

LUCATElli, M. V.. Proposta de Aplicação de Manutenção Centrada em Confiabilidade em Equipamentos Médico-Hosptitalares. Tese (Doutorado em Engenharia Elétrica). Universidade Federal de Santa Catarina,Florianópolis, 2002.

MÁRQUEZ, A. C. et al. The maintenance management framework. A pratical view to maintenance management. Journal of Quality in Maintenance Engineering,London, 17 mar. 2009. v. 15, n. 2, p. 167-178. crossref

MENDES, A. A. Manutenção centrada em confiabilidade: uma abordagem quantitativa. 2011. Dissertação (Mestrado em Engenharia) - Universidade Federal do Rio Grande do Sul, 2011.

MONTEBELLO, A. E. S. Configuração, reestruturação e mercado de trabalho do setor de celulose e papel no Brasil. 2010. Tese (Doutorado). Escola Superior de Agricultura “Luiz de Queiroz”, Piracicaba, 2010.

MORAES, F. A. B. Modelo para avaliação do consumo específico de madeira e insumos energéticos no processo de produção de celulose e papel. 2010. 212 p. Tese (Mestrado em Gestão operacional da produção) - Programa de Pós-Graduação em Engenharia de Produção, Centro Universitário de Araraquara, Araraquara, 2004.

MIRSHAWKA, V.; OLMEDO, N. L. Manutenção: Combate aos custos de não-eficácia - A vez do Brasil. São Paulo: Makron Books, 1993.

MOUBRAY, J. Manutenção Centrada em Confiabilidade: Reliability-Centered Maintenance - RCM. Trad. Kleber Siqueira. São Paulo: Aladon, 2000.

NAKAJIMA, S.. Introdução ao TPM: Total Productive Maintenance. IMC Internacional Sistemas Educativos Ltda.: São Paulo, 1989.

PALARCHIO, G. Why PM Programs Do Not Significantly Reduce Reactive Maintenance. Disponível em: <http://www.mt online.com/articles/0601_viewpoint.cfm>. Acesso em: 02 jul. 2014.

PALMER, D. Maintenance Planning and Scheduling Handbook. New York: McGraw-Hill, 2000.

PATTON, J D. Preventive Maintenance. New York: Instrument Society of America, 1995.

PINTO, A. K; XAVIER, J. N. Manutenção: Função estratégica. Rio de Janeiro: Qualitymark, 2005. 
PIOTTO, Z. C. Eco-eficiência na Indústria de Celulose e Papel: estudo de caso. 2003. 379 p. Tese (Doutorado em Engenharia) - Programa de Pós-Graduação em Engenharia Hidráulica e Sanitária, Escola Politécnica da Universidade de São Paulo, São Paulo, 2003.

RAUSAND, M. Reliability centered maintenance. Reliability Engineering and System Safety Vol. 60, p. 121- 132, 1998.REALIASOFT. Life data analysis reference. Reliasoft Corporation. Disponível em:<www.weibull.com/lifedatawebcontents.htm> Acesso em: 20 de set. 2014

RELIASOFT. System analysis reference, reliability, availability and optimization. Tucson: Reliasoft Publishing, 2003. Disponível em <www.weibull.com>. Acesso em: 23 de set 2014.

RIGDON, S. E.; BASU, A. B. Statistical methods for the reliability of repairablesytems. New York : John Wiley\& Sons, 2000.

SELLITTO, M. A. Formulação estratégica da manutenção industrial com base na confiabilidade dos equipamentos. Revista da Produção, v 15, n. 1, p. 44-59, 2005. crosşref

SILVA A.C. M.Modelo para o planejamento de manutenção baseado em parâmetros de degradação. 2010.116 p Tese (Mestrado em Manutenção Industrial) - Programa de Pós-Graduação em Engenharia de Produção, Universidade Federal do Pernambuco, Recife, 2010.

SILVA, C. L. Competitividade internacional da indústria de papel de imprimir e escrever brasileira sob a ótica da cadeia de valor. 2002. 270 p. Tese (Doutorado em Engenharia de Produção ) - Programa de Pós-Graduação em Gestão de Negócios, Universidade Federal de Santa Catarina, Florianópolis, 2002.

SILVA, F. G. Conversão do processo kraft em soda-DDA( sal di-sódio de 1,4-dihidro-9,10-dihidroxi antraceno) para madeira de eucalipto. 1994. 194 p. Tese (Mestrado em Ciências) - Programa de Pós-Graduação em Ciência e Tecnologia de madeiras, Universidade de São Paulo, Piracicaba, 1994.

SLACK, N.; CHAMBERS, S.; JOHNSTON, R. Administração da produção. 2. ed. Atlas: São Paulo, 2008.

SOUZA, F. J. Otimização do Pilar "Manutenção planejada" da TPM através da utilização do RCM para nortear as estratégias de manutenção. 2004. 115 p. Tese (Mestrado em Engenharia) - Programa de Pós-Graduação em Engenharia de Produção, Universidade Federal do Rio Grande do Sul , Porto Alegre, 2004.

TAKAHASHI, Y; OSADA, T. Manutenção Produtiva Total. São Paulo: Instituto IMAM, 1993.

TAVARES, L.A. Administração Moderna da Manutenção. Rio de Janeiro: Novo Pólo Publicações e Assessoria Ltda, 1999.

XENOS, H. G. Gerenciando a Manutenção Preventiva: o caminho para eliminar falhas nos equipamentos e aumentar a produtividade. Belo Horizonte. Nova Lima: IDNG Tecnologia e Serviços Ltda, 2004.

ZAIONS, D. R. Manutenção Industrial com Enfoque na Manutenção Centrada em Confiabilidade. 2003. 115 p. Tese (Mestrado em Engenharia) - Curso de Pós-Graduação em Engenharia de Produção), Universidade Federal do Rio Grande do Sul, 2003.

WIREMAN, T. Developing performance indicators for managing maintenance. New York: Industrial Press Inc., 1998.

WOLF, E. O uso do lodo de estação de tratamento de água e resíduos da indústria de celulose (dregs, grits e Lama de cal) na produção de cerâmica vermelha. 2008. 188 p. Tese (Doutorado em Engenharia de Produção ) Programa de Pós-Graduação em Gestão de Negócios, Universidade Federal de Santa Catarina, Florianópolis, 2008.

WYREBSKI, J. Manutenção Produtiva Total: Um Modelo Adaptado. 1997. 124 p. Tese (Mestrado em Engenharia). Pós-Graduação em Engenharia de Produção e Sistemas, Universidade Federal de Santa Catarina. Florianópolis, 1997.

\section{Dados dos autores}

\section{Nome completo: Giglliara Segantini de Menezes}

Filiação institucional: Universidade Federal do Espírito Santo

Departamento: Departamento de Engenharias e Tecnologia

Função ou cargo ocupado: Engenheira de Produção 
Endereço completo para correspondência: BR 101 km 60 Norte, Bairro Litorâneo, São Mateus, ES, Brasil, CEP 29932-540

E-mail: giglliara@hotmail.com

Nome completo: Maiquel Moreira Nunes Santos

Filiação institucional: Universidade Federal do Espírito Santo

Departamento: Departamento de Engenharias e Tecnologia

Função ou cargo ocupado: Mestrando em Energia

Endereço completo para correspondência: BR 101 km 60 Norte, Bairro Litorâneo, São Mateus, ES, Brasil, CEP 29932-540

E-mail: maisanto@hotmail.com

Nome completo: Gisele de Lorena Diniz Chaves

Filiação institucional: Universidade Federal do Espírito Santo

Departamento: Departamento de Engenharias e Tecnologia

Função ou cargo ocupado: Professora

Endereço completo para correspondência: BR 101 km 60 Norte, Bairro Litorâneo, São Mateus, ES, Brasil, CEP 29932-540

E-mail: gisele.chaves@ufes.br

Submetido em: 04-06-2015

Aceito em: 14-09-2015 